Sharif University of Technology
Scientia Iranica
Transactions E: Industrial Engineering
hCIENTIA

\title{
Metaheuristics for a new MINLP model with reduced response time for on-line order batching
}

\author{
L. Hojaghani ${ }^{a}$, J. Nematian ${ }^{\text {b,* }}$, A.A. Shojaie ${ }^{\text {a }}$, and M. Javadic \\ a. Department of Industrial Engineering, South Tehran Branch, Islamic Azad University, Tehran, Iran. \\ b. Department of Industrial Engineering, University of Tabriz, Tabriz, P.O. Box 51666-147666, Iran. \\ c. Department of Mechanical Engineering, South Tehran Branch, Islamic Azad University, Tehran, Iran.
}

Received 21 July 2018; received in revised form 17 August 2019; accepted 28 December 2019

\author{
KEYWORDS \\ Warehousing; \\ On-line order \\ batching; \\ Warehouse blocking; \\ Zoning system; \\ Idle time; \\ $\mathrm{ABC}$ meta-heuristic \\ algorithm; \\ ACO meta-heuristic \\ algorithm.
}

\begin{abstract}
Companies are looking for effective strategies to improve warehouse performance quality due to customers dissatisfaction of service. The order picking process is one of the main warehouse management strategies. As the inventory of stored items and the number of orders increased, the picking process and response time became more important. Effective coordination between order batching and order picking process is essential to improve the efficiency of the warehouse management system. In this paper, a novel MixedInteger Nonlinear Programming (MINLP) model for on-line order batching is proposed for improving the warehouse performance, which in turn results in the reduction of the response and idle times. The proposed method takes aim at the investigation of order classification for the first time in the picker-to-part system as a manual picking system and an online order batching system, with the intent of minimizing the turnover time and idle time. Besides, an order batching model in a blocked warehouse using a zoning system is proposed which is called Online Order Batching in Blocked Warehouse with One Picker for each Block (OOBBWOPB). The mentioned model is solved by two algorithms: Artificial BeeColony (ABC) algorithm and Ant-Colony (ACO) algorithm. Two numerical case studies are defined and analyzed using MATLAB software. According to the results compared with the results of Zhang et al. (2017) the proposed model shows better performance and the average customer order response time is significantly reduced (2017) and the ACO yields better results than $\mathrm{ABC}$.
\end{abstract}

(C) 2021 Sharif University of Technology. All rights reserved.

\section{Introduction}

In a supply chain, efforts, cooperation, and coordination of all facilities are the key factors to achieve successful supply chain management. In order to deliver orders and services to customers at the lowest cost and specified time, each facility must optimize its

*. Corresponding author. Fax: +98 4133354153

E-mail address: jnematian@tabrizu.ac.ir (J. Nematian)

doi: $10.24200 /$ sci. 2019.51452 .2185 operations [1,2]. A distribution warehouse includes many operations and order picking is considered as one of the most important parts of such operations. According to Bartholdi and Hackman [3], order picking has about $55 \%$ of total activities costs in a warehouse. Tompkins et al. [4] indicated that the travel time includes approximately $50 \%$ of all order picking operations. Order picking is a time-consuming and energy-consuming process, which could include approximately $60 \%$ of the human activities in the warehouse. When promoting order picking operations, decreasing human interference in the process is a crucial fac- 
tor. To achieve this goal, various methods have been developed. Zoning is another method, which could effectively reduce the travel distance of the pickers. In this case, each picker only picks up and picks in his own predefined area [5].

The zoning technique classifies pick locations into some subclasses (i.e. zones) and each zone has its exclusive one or more pickers. Reducing travel time and reducing traffic congestion is one of the most important advantages of zoning technology [6]. The progressive zoning system is called the picking and delivery system, which divides the picking line into picking zones. Then, each zone is dedicated to an exclusive picker, and all of them are often linked together with the help of a conveyor in the warehouse [7]. The algorithm is mainly suitable for small and medium-sized commodities that can be stored and accessed in relatively small and available pick locations. In this regard, the commodities such as home appliances, health and beauty, office, and food can be mentioned [8].

Therefore, warehousing experts realize that the order picking process is the most important factor in increasing productivity. The process of order picking is a warehouse action related to data restoration (article units) from their storage place in line with meeting customer orders' satisfaction, both internally and externally [9].

The problem arises because a large number of purchased goods and goods enter the warehouse, but they are gradually sold to customers. The issue of order picking is critical to every supply chain, because problematic activity in the field bears heavy costs, resulting in unsatisfactory customer services. Although extensive attempts have been made to mechanize the order picking process, a large number of systems with manual intervention have still been discovered [10,11]. This kind of handy order picking process falls into two classes [12]: First, Picker to parts system; in this system, the order picker arrives to the warehouse and gathers the ordered goods. Second, the parts to picker system; in this case, the mechanized restoration system delivers the ordered goods to the picker. In the first system, which is investigated in this study, three operative activities are identified [5]: Determining the location of the items, transferring the ordered items to the picking order, and determining the path for the pickers in the warehouse. The purpose of this research is to investigate the second activity of the system, in which various orders placed by the customers are combined in batches and released together for pickup. This has been proven to be essential for improving the efficiency of operations in the warehouse [13].

Order batching as one of the most prominent approaches in the order picking process, could greatly enhance this process performance by minimizing the processing time [14-16]. Regarding the accessibility of the orders, two manners are assumed [17]: The offline (static) batching orders, in which all orders are known from starting time of the shift, and the online (dynamic) batching orders, in which the orders are accessed dynamically. To solve the problems raised in the field of the online batching, time window is the most popular strategy, which falls into two fundamental categories: Fixed Time Window Batching (FTWB) and Variable Time Window Batching (VTWB). Nevertheless, these solutions are not respondents to an environment, where type and quantity of the orders are changing permanently. Considerable amounts of undelivered orders will be prepared to be delivered in a fixed period of time order in the FTWB section along with those scenarios having a relatively high arrival rate [10]. On the contrary, a long time is required to make the orders ready to be delivered in the VTWB section and relatively low arrival rate scenarios. The FTWB is known as a time-based batching process [18] and the VTWB is known as a quantity-based batching role [5]. According to recent researches [18], a hybrid rule-based algorithm has better performance than the time-based and quantity-based algorithms, in terms of saving time. Thus, a hybrid rule-based process would be able to substantially improve time-saving and wage costs in terms of arrival rates, picking devices, and time intervals. Furthermore, according to the findings of the study it can be claimed that the hybrid method is the best method of categorization in on-line order systems [19].

Due to the mentioned observations, in this research, for the first time the order batching model in a blocked warehouse is introduced named Online Order Batching in Blocked Warehouse with One Picker for each Block (OOBBWOPB). This is examined by an online order entry system using a nonlinear programming model based on the Artificial Bee Colony (ABC) algorithm and the Ant Colony (ACO) algorithm metaheuristic method.

The $\mathrm{ABC}$ is one of the most recent algorithms defined by Dervis Karaboga in 2005 and inspired by the intelligent behavior of honey bees [20]. Due to its simplicity and effectiveness, it has attracted much attention in recent years [21]. In this algorithm, a set of honey bees, called swarm, can successfully accomplish tasks through social cooperation. In the $\mathrm{ABC}$ algorithm, there are three types of bees: employed bees, onlooker bees, and scout bees. The employed bees search for food around the food source in their memory; meanwhile they share the information of these food sources to the onlooker bees. The onlooker bees tend to select good food sources from those found by the employed bees. The sources with higher quality (fitness) will have a greater chance of being selected by onlooker bees than food sources with lower quality. 
The scout bees are translated from a few employed bees, which abandon their food sources and search for new ones. In the algorithm, the first half of the swarm consists of employed bees, and the second half constitutes the onlooker bees. The number of employed bees or the onlooker bees is equal to the number of solutions in the swarm. The ABC generates a randomly distributed initial population of SN solutions (food sources), where SN denotes the swarm size [22].

The ACO is one of the most recent techniques for approximate optimization that was introduced by Dorigo in 1990. The source of inspiration for these algorithms are real ant colonies. More specifically, ACO is inspired by the ants foraging behavior [23]. The core of this behavior is the indirect communication between the ants through chemical pheromone traces, which enables them to find short paths between their nest and food sources. This characteristic of real ant colonies is used in the ACO algorithm to solve, for example, discrete optimization problems [24,25]. these algorithms solve this model to form the initial order batches and to improve the batches to improve the response time and reduce the unemployment time of the operators.

The OOBBWOPB model includes the customer order assignment to minimize the processing time, which is closely associated with the Order Batching Problem (OBP). In this model, the entire warehouse is divided into several blocks, and each block is assigned a picker. The ultimate goal in this method is tuning the batches to optimize the turnover and idle time.

The follow-up content of this study is arranged as follows: In Section 2 a review of the OBP literature is presented. Section 3 develops a new optimization approach for minimizing customers orders delivery time and the best picking time. In Section 4, two metaheuristic algorithms are used to solve the model and the results are analyzed.

\section{Review of the literature}

In today competitive world, companies are constantly trying to reduce transportation costs, while the bulk of warehousing activities are the transportation of goods. Given that the order response process is very costly for companies and determines the level of customer service, the role of warehouse management in a company to store and distribute customer orders is very important. In a Competitive Supply Chain (CSC) system, the speed of response to orders indicates the level of product and service quality, and the goal of Supply Chain Management (SCM) is to increase the value of the organization by increasing the level of service to the customer. Also, competition between companies in the transportation sector is basically based on time, cost and level of customer service. Effective supply chain management is one of the main business survival, meanwhile, the use of information technology in supply chain activities has increased the potential for value creation in the chain. Generally speaking, supply chain management emphasizes the continuous improvement of adaptability and flexibility of enterprises, and the ability to respond to market changes quickly and effectively. In recent years, extensive research has been done on the supply chain e.g., Nia et al. [26], Marandi and Zegordi [27], Teimoury and Kazemi [28], and Chaharsooghi and Sajedinejad [29].

In large warehouses with the online ordering system and a large number of orders, we do not know the exact time of arrival of orders and the content of orders, therefore, to reduce response time and costs companies have turned to the order batching system. Elsayed et al. [30] investigated the penalty function of batching operation in a warehouse with the AS/RS system. According to $\mathrm{Gu}$ et al. [31], there is no much research on order batching, and the issue needs to be addressed in different systems and conditions. As previously mentioned, according to Henn's research, warehouses with dynamic ordering systems (online systems) in which there is no information about the time of order entry and its items in the order list, it is better to study time window batching problem. In this view, in order to reduce response time, we specify the ordered items to be placed in batches. Richards [32] have studied an online ordering system in a single-block warehouse with the purpose of reducing the response time of orders and determining the best route for operators.

Combining on-line batch programming patterns with findings of off-line order batching, Henn et al. $[14,16,33]$ developed the underlying on-line algorithm. Henn et al. [15,16,34] developed a two-competitive online algorithm using competitive analysis for the on-line order batching system. Henn et al. [34] have developed a model for batching orders and examined how to combine customer orders into one batch to reduce the length of the collection route. To solve the model, two approaches based on Tabu search have been proposed. the first is a (classic) Tabu Search (TS), and the second is the attribute-based hill climber (ABHC). They have shown that the methods, enabling the warehouse to respond to orders more effectively.

Zhang et al. [18] studied the problem of online order batching with Several operators in a single-block warehouse. FTWB is known as time-based batching process and VTWB is known as quantity-based batching rule. According to researchers [18], A hybrid rule-based algorithm provides better performance than time and quantity in terms of time-saving. Bahrami et al. [36] simulated different ordering policies in the Picker-to-part systems and then statistically analyzed the simulation results by designing experiments.

Recently, Van Gill et al. [37] have investigated 
the issue of increasing order picking efficiency by considering all storage, classification, zoning, and routing issues. The main purpose of this research was to identify the impact of these elements on response time reduction. It is worth noting that this research clearly analyzes the relationship between storage, classification, zoning, and routing for the first time.

One of the key and fundamental issues in every company is warehousing management which can significantly affect chain costs [38]. Zoning and batching are two major factors for improving the performance of the warehouse which in turn results in reducing the response time and increasing the customers satisfaction level [17]. Zoning and batching issues are often applied simultaneously in warehouses. However, in most literature, they are studied separately.

Choe [39] developed a single-block framework for picking locations and modeled the sorting function as a single automated server. This researcher has studied both FTWB and VTWB. In fact, the time of arrival of orders has been the main factor of their research. Tang and Chew [40] and Le-Duc and de Koster [5] studied VTWB. In their study, they investigated the exponential and/or processing times, and single-server station. In these studies, the sorting function is not directly modeled, and since the relationship between sorting and picking has not been determined, their results are limited when the knowledge about the sorting function is limited. Parikh and Meller [41] studied the applicability of batch picking and zone picking to existing distribution centers and proposed a cost model for choosing between picking strategies.

An analytical approach was developed by Van Nieuwenhuyse and de Koster [6] in order to estimate the throughput time of the expected system in an online ordering system for both VTWB and FTWB. All of these studies were conducted in randomized models.

Arranging a route for the means of transportation in the warehouse is the most important activity in the warehouse because it takes a long time to travel on this route compared to other activities. Therefore, it is a very important and inevitable problem to find the shortest route for goods in the warehouse for the picking and delivery of goods [42].

Matusiak et al. [43] proposed a simulated annealing algorithm for order batching in a warehouse with three cross-aisles. Considering on-line shopping, Valle et al. [44] investigated the problem of order batching and picker routing. Menéndez et al. [45] introduced a new routing method based on the ideas of the combined strategy for the OBP. In the context of the OBP, Menéndez et al. [46] proposed a heuristic approach based on the Variable Neighborhood Search method for picker routing a specific order due date.In the following, Jiang et al. [47] have also reviewed the ordering of orders and sequencing issues with regard to the pickand-sort strategy in the online supermarket.

In recent years, extensive research has been conducted on the supply chain of which Menéndez et al. [46] and Lin et al. [48] and Hong and Kim [49] can be mentioned. Hong introduced a route-selecting model with an s-shape method in parallel-aisles in order to reduce the response time of the OBP. Considering all sub-problems of order batching, batch assignment and sequencing, as well as picker routing problems, Scholz et al. [13] proposed an approach to improve the operational efficiency of the distribution warehouse for the first time. In this paper, we have studied the effects of batching and zoning on the average throughput time of customers orders. Moreover, in this research, operator routing within blocks is based on s-shaped routing.

This paper extends the work of Tang and Chew [40], Le-Duc and de Koster [5], Parikh and Meller [41], and $\mathrm{Yu}$ and De Koster [17] into a multiple zones level. Recently, due to the emergence of e-commerce and ebusiness, global supply chain management pays special attention to small and frequent order delivery with lower total costs [50].

Therefore, to achieve efficient supply chain management, the picking and delivery system plays a major and critical role. Gibson et al. [51] asserted that most researches on collecting orders, have used the classic picker-to-parts system. In this traditional system, the benchmark for performance measurement is the vehicle or operator travel time. Therefore, by reducing the travel time, we can significantly reduce the system costs. Now considering that in pick-and-pass systems, the route and the length of the route are fixed for one operator or vehicle, to reduce the cost of travel, we should reduce the number of order batches and use the maximum capacity of each batch. This process can reduce the number of fixed route, thereby reducing response time [8].

In Pan investigation, based on group genetic algorithm a batching method is proposed which decreases the processing time of order collection. In this method, the issues of line balancing and reduction of the formed batches are considered.

In order batching, each order can have different numbers and items. The order picker must go through the entire warehouse with a vehicle of a certain volume and collect the ordered items. With the increase of order items as well as the number of orders received in a period of time, this process is very time-consuming and as a result, the response of orders becomes difficult. This problem is called NP-hard. If there are at most two orders per batch, it can be solved in polynomial time [52]. So far different models for order batching are proposed, some of which include: Elsayed et al. [30], 
Chen et al. [50], Gademann and Velde [52], Henn and Schmid [10], Kulak et al. [53], and Jiang et al. [47].

The previous researches did not consider the issue of warehouse blocking, and the lack of research regarding the classification of the online order batching system is very evident. However, according to some studies [8], the impact of warehouse blocking on the reduction of the order batch time and the improvement of customer satisfaction is obvious and significant. Hence, in this paper a new nonlinear model is proposed for online order batching by considering the blocked warehouse.

\section{On-line Order Batching in Blocked Warehouse with One Picker for each Block (OOBBWOPB)}

\subsection{Problem description}

According to Choe [39], there are two different viewpoints for order batching: Time window batching and proximity of pick location. Also, according to Zhang, the function of order batching is based on the time index. The ordering system basically conforms to the queuing process, and it operates in batch generation and batch operations.

This paper investigates the effect of batching on the reduction of the orders response time and the idle time of operators. As you know, the ordering system is based on queuing systems, which operate on batch generation and batch operation. The batches formation take place through different methods. According to Zhang, the hybrid method, which combines two methods of FTWB and VTWB, is one of the best approaches that applies both volumetric capacity constraints of the batches and the time duration of the batch formation. In fact, the purpose of batching is to specify which orders are best placed in a batch and when it is better for the batches to be dealt with. The standard response process of orders batch generation system is shown in Figure 1. It is similar to the Zhang arrangement, except that the latter considered the warehouse as an integrated unit. Each operator collects the ordered items from the relevant racks according to the inventory of the entire warehouse. In this study, the warehouse is divided into $k$ blocks, and an operator is assigned to each block. The formed batches are segregated based on the items of each block during operation, and the list of all blocks is sent to the operators simultaneously. The completion time of an order batch is the time period during which orders collection in all blocks is terminated.

In the illustration, the arrive time is the moment when the customer order is entered into the system, and enter time is the moment at which the prepared batch is entering the batch operation. Between these two points, there is a batch time, which is the time interval between the arrive and enter time; This time interval extends from the first order batch to the batch which is ready for the next stage. The prepared batches are operated according to First In-First Out (FIFO) system, and the duration of batch queuing is called the wait time. Order batch items are segregated according to which block they belong to and are sent to the picker of the corresponding block through a separate list for each block. It is worth mentioning that the sum of all lists items related to the $k$ block is equal to the sum of the batch items. In addition, when the picking system is used to collect items, the goods associated with each order can be identified. In this way, the picker is labeled during the collection. All blocks are similarly equipped with parallel aisles, and there is a depot in front of the leftmost side of the aisle inside each block. It should be noted that the warehouse layout is based on the random storage system. The service time includes the time interval for the picker to receive the list and deliver the collected items to the warehouse. At this time, it

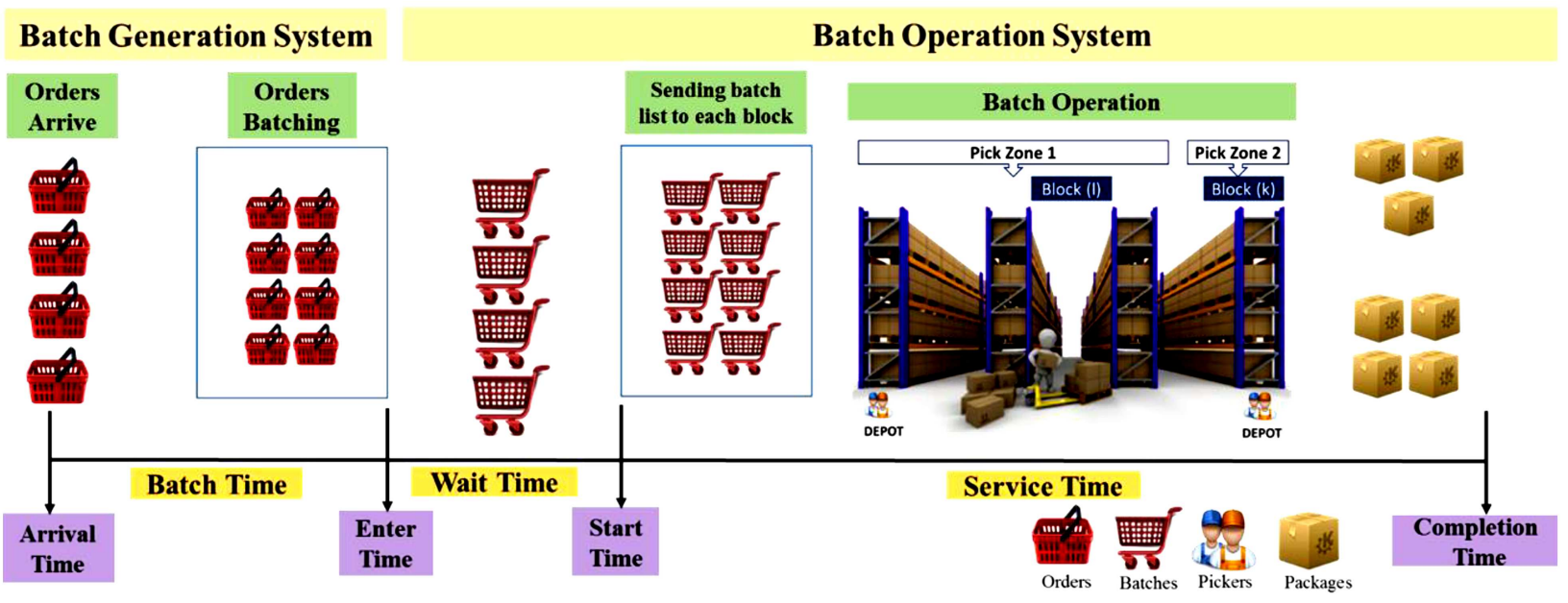

Figure 1. The Online Order Batching in Blocked Warehouse with one Picker for each Block (OOBBWOPB) system: Batch generation system and batch operation system. 
is not possible to pause the process and edit the list. When all the batch items are collected and delivered from different blocks, a specific batch is completed.

According to the aforementioned statement, in a warehousing system, the improvement of the pickerto-parts response system has been examined. In this system, the warehouse has benefited from the Automatic Storage and Retrieval System (AS/RS). In this regard, new influential parameters involved in the order picking process, have been identified. By analyzing these parameters, not only can the existing problems such as wasting operator time and increasing the length of the route be solved, but the response time has also been improved, thereby increasing the overall efficiency of the system. Regarding the fixed route connected length of different sections of ASRS warehouse, we decided to decrease the number of batches of this fixed route to minimize the response time (turnover time) and total picker idle time in each block which in turn could lead to the optimization of the cost operation.

\subsection{Current batching rules}

For batching rules, shown in Figure 2, each step is described below:

- First step: Customer orders enter the batch generation system at the start time $t^{\text {start }}$. The maximum capacity of the order picking a vehicle for block $k$ is $Q_{k}$

- Second step: In FTWB $\left[t^{\text {start }}, t^{\text {end }}\right]\left(t^{\text {end }}=t^{\text {start }}+t^{b}\right.$, where $t^{b}$ is the batching time), all arriving customer orders are assigned to one batch, if the quantity of the items $S \leq Q_{k}, t^{b} \leq T$, and $t^{b} \leq t^{T Q}$, where $S$ is sum of the volume of items related to each block in the batch, $T$ is upper bound for batching time and $t^{T Q}$ is the time needed for entering orders to a batch to reach the specified volume of $T Q$; otherwise we can generate new batch;

- Third step: One should back to the second step until the ending time of the system;

- Fourth step: The generated batches are entered into the batch operating system.

Table 1 shows the algorithm for batch generation and batch operation according to the program written by the MATLAB R2013b software.

\section{3. $О О В B W O P B$ optimization model}

The heuristic algorithms of ABC and ACO are used to formulate and solve the optimized Mixed Integer Nonlinear Programming (MINLP) model for online batching of orders. In order to analyze the problem, a model that requires complete information of all incoming orders is proposed. The constants and variables used in this model are listed in Tables 2 and 3 , respectively.

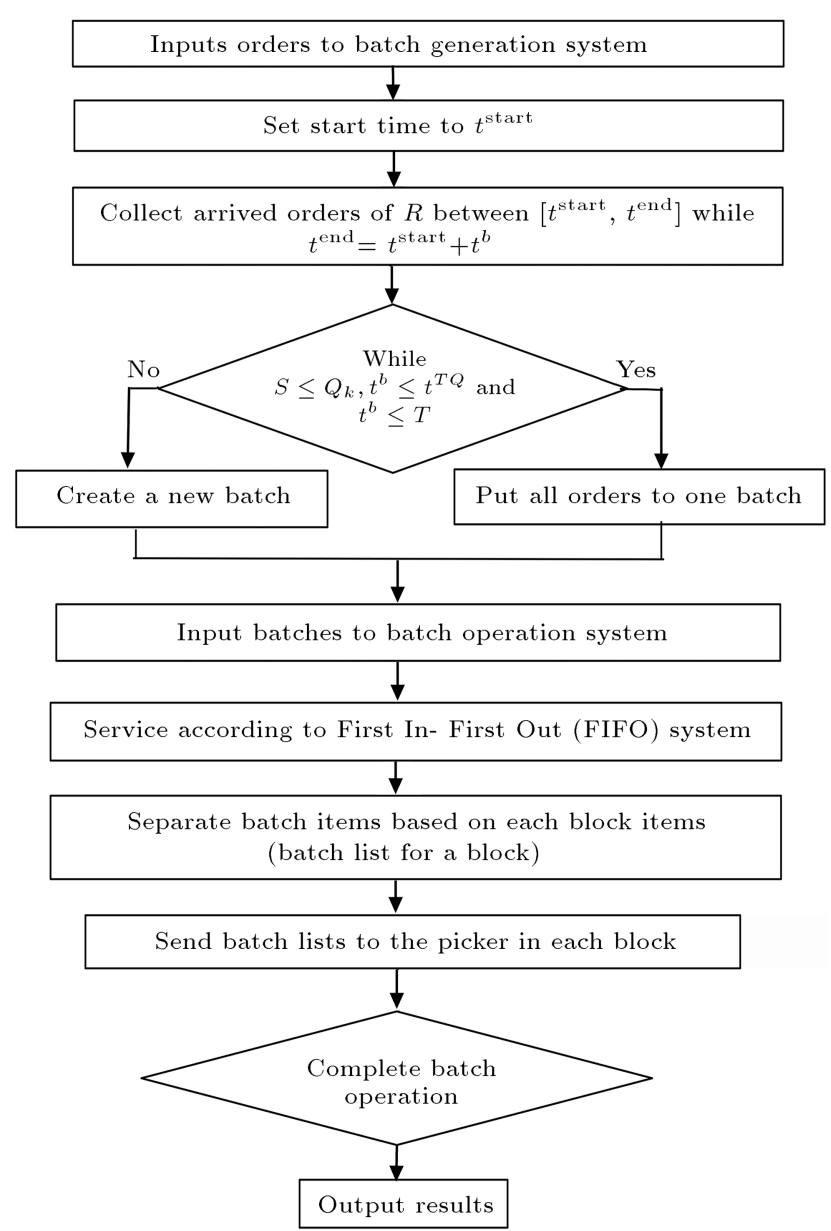

Figure 2. The flowchart of batch generation and batch operation system.

Therefore, due to the aforementioned constants and variables, according to the $\mathrm{ABC}$ and $\mathrm{ACO}$ algorithms the OOBBWOPB is modeled as follow.

The objective function (1) minimizes the sum of the maximum response time of the order and the total amount of idle time of the picking operator in each block:

$$
\min \max _{j} \in\{1,2, \ldots, m\}\left\{T_{j}^{\mathrm{response}}+\sum_{k=1}^{l} I T_{j k}\right\} .
$$

Constraint (2) ensures that each order is limited to one batch:

$$
\sum_{j=1}^{m} x_{i j}=1, \quad \forall i \in\{1, \ldots, n\} .
$$

Constraint (3) ensures that all items of batch $j$ are assigned to the pickers:

$$
\sum_{i=1}^{n} q_{i} . x_{i j}=\sum_{k=1}^{l} y_{j k}, \quad \forall j \in\{1, \ldots, m\} .
$$

Constraint (4) ensures that the volume of goods allocated to each picker is not greater than the capacity of 
Table 1. Batch generation and batch operation algorithm.

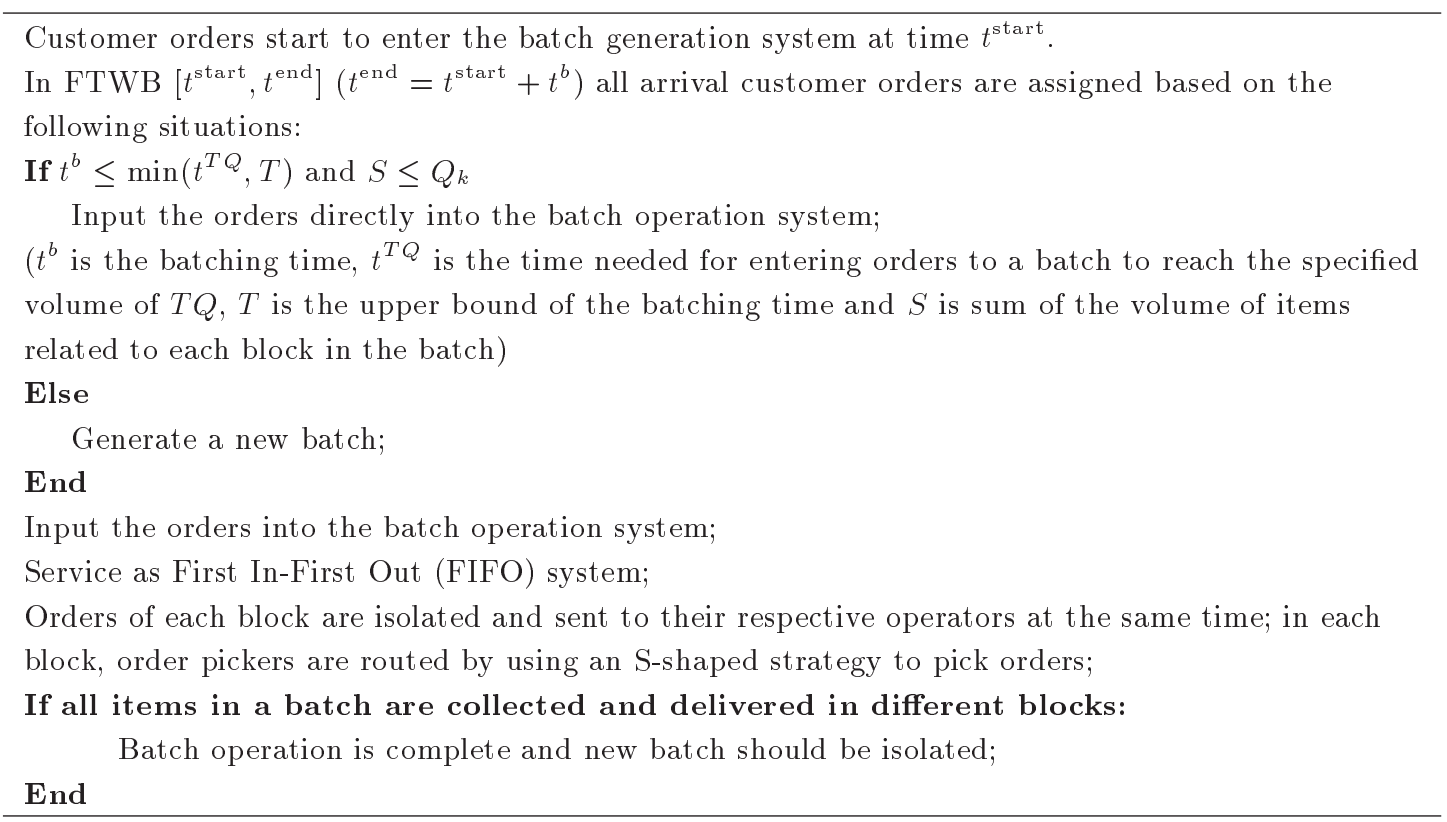

Table 2. The model constants.

\begin{tabular}{ll}
\hline$n$ & Number of customer orders \\
$m$ & The upper limit of the number of batches (a trivial upper bound can be $n=m)$ \\
$T$ & Upper bound of the batching time \\
$A$ & Total number of aisles \\
$P$ & Number of pickers for a block \\
$L$ & Number of storage locations \\
$W_{K}$ & Center to center distance between two aisles \\
$L_{k}$ & Length of aisles \\
$x_{k}^{v e h}$ & The distance where the transport vehicle of the block $k$ will travel to delivery place \\
$t_{i}^{a}$ & Arrival time of customer order $i$ to the order batching system where $\left(0<t^{a}{ }_{i} \leq t^{a}{ }_{i+1}\right)$ \\
$t_{\text {setup }}$ & Setup time (time needed for each picker before starting to prepare each batch) \\
$q_{i}$ & Number of items of custom order $i$ \\
$q_{k}$ & The capacity of the vehicle for the block $k$ \\
$Q_{p}$ & Quantity of goods \\
$v_{\text {travel }}$ & Travel speed, the distance each picker can travel in the unit of time \\
$v_{\text {pick }}$ & The picking speed, the number of items the picker searches and takes in the time unit \\
$v_{v(k)}$ & The speed of the vehicle $k$ \\
$k$ & Number of the warehouse blocks (each block has been assigned by an operator) \\
$I$ & Upper bound of the warehouse blocks number \\
$T Q$ & Sum of the capacity of the order picking vehicles for all blocks \\
\hline
\end{tabular}

the transport vehicle associated with the picker:

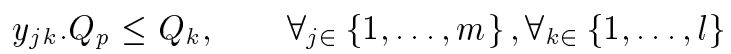

Constraint (5) calculates the entrance time to the service queue:

$$
\left.t_{j}^{\text {enter }}=t_{j}^{\text {batch }}+\min \left\{x_{i j} \cdot t_{i}^{a}\right\}, \quad \forall_{j \in\{1, \ldots, m}\right\} .
$$

Constraint (6) calculates the duration of the batching time:

$$
t_{j}^{\text {batch }}=\min \left\{t_{j}^{T Q}, T\right\}, \quad \forall_{j \in\{1, \ldots, m\} .}
$$

Constraint (7) calculates the waiting time for the order batching.

$$
t_{j}^{\text {wait }}=t_{j}^{\text {start }}-t_{j}^{\text {enter }}, \quad \forall_{j \in\{1, \ldots, m\}} .
$$

Inequality (8) shows the start time of the $j$ batch and ensures that when the total goods related to the batch 
Table 3. The model variables.

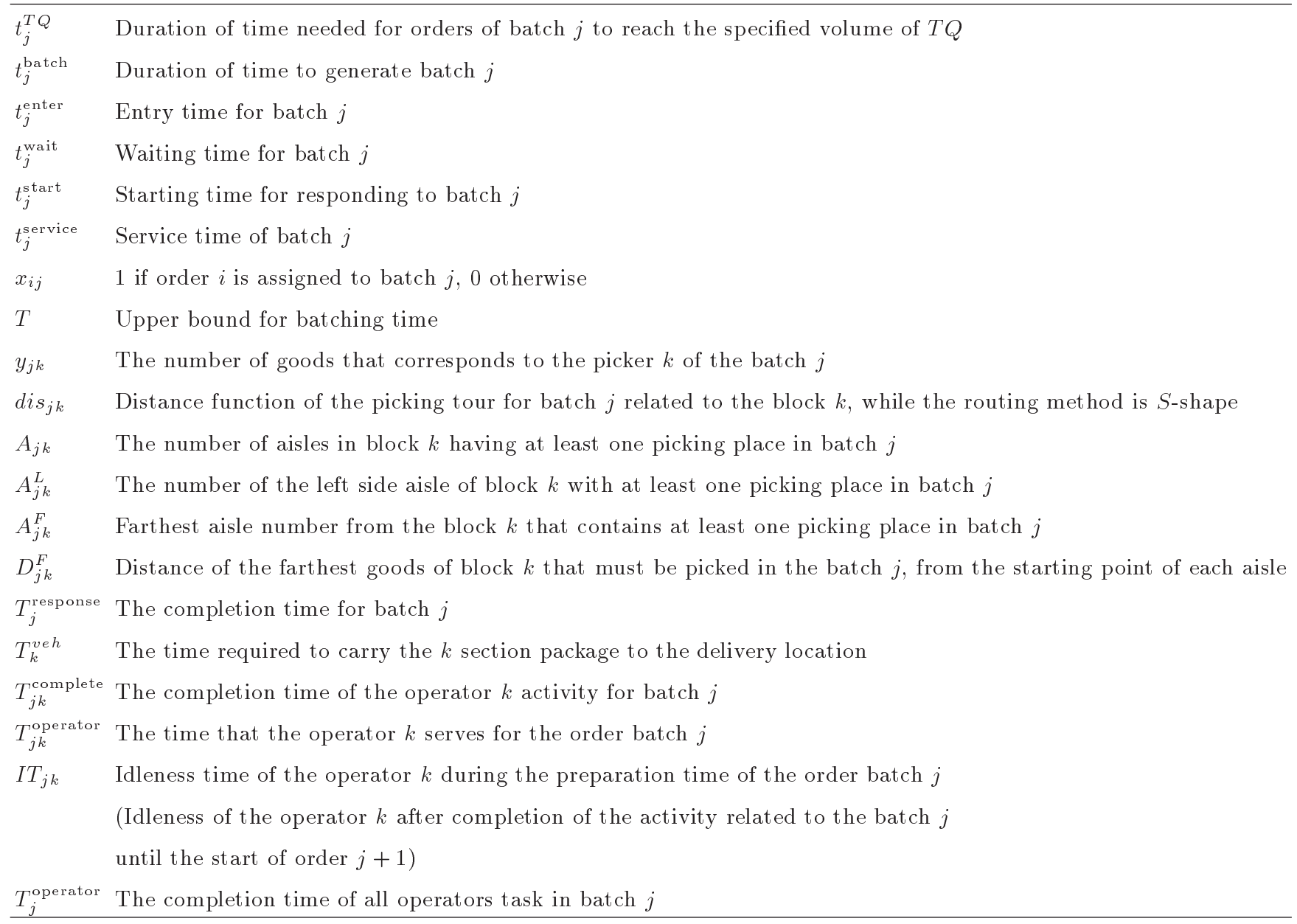

are identified, services can be started for each category:

$$
t_{j}^{\text {start }} \geq \max \left\{x_{i j} \cdot t_{i}^{a}\right\}, \quad \forall j \in\{1, \ldots, m\} .
$$

Inequality (9) ensures that the system sends the list of each order batch to the picking operator. At this time, all operators have completed the work on the previous category.

$$
t_{j+1}^{\text {start }} \geq \max _{k}\left\{T_{j k}^{\text {complete }}\right\}, \quad \forall_{j \in\{1, \ldots, m\} .}
$$

Eq. (10) calculates the duration of service time for each category and ensures that the termination of service to each order batch is the time when all the goods belonging to that category have arrived at the place of delivery. $T_{j k}^{\text {complete }}$ and $T_{k}^{\mathrm{veh}}$ will be calculated in Eqs. (11) and (16).

$$
\begin{gathered}
T_{j}^{\text {service }}=\max _{k}\left\{T_{j k}^{\text {complete }}+T_{k}^{\text {veh }}\right\}, \\
\forall j \in\{1, \ldots, m\} .
\end{gathered}
$$

Eq. (11) calculates the completion time of each operator work in each order batch:

$$
\begin{aligned}
T_{j k}^{\text {complete }} & =T_{j}^{\text {start }}+T_{j k}^{\text {operator }}, \\
& \forall_{j \in\{1, \ldots, m\},} \forall_{k \in\{1, \ldots, l\} .}
\end{aligned}
$$

Eq. (12) calculates the completion time of each order batch:

$$
\left.T_{j}^{\text {response }}=\max _{k}\left\{T_{j k}^{\text {complete }}\right\}, \quad \forall_{j \in\{1, \ldots, m}\right\} .
$$

Eq. (13) calculates the interval between service start points of two consecutive order batches.

$$
T_{j}^{\text {operator }}=\max _{k}\left\{T_{j k}^{\text {operator }}\right\}, \quad \forall j \in\{1, \ldots, m\} .
$$

Eq. (14) calculates the idling time for each operator during the service completion of each batch:

$$
\begin{aligned}
I T_{j k} & =T_{j}^{\text {operator }}-T_{j k}^{\text {operator }}, \\
& \forall j \in\{1, \ldots, m\}, \quad \forall_{k \in}\{1, \ldots, l\} .
\end{aligned}
$$

Eq. (15) calculates the duration of service time of the 


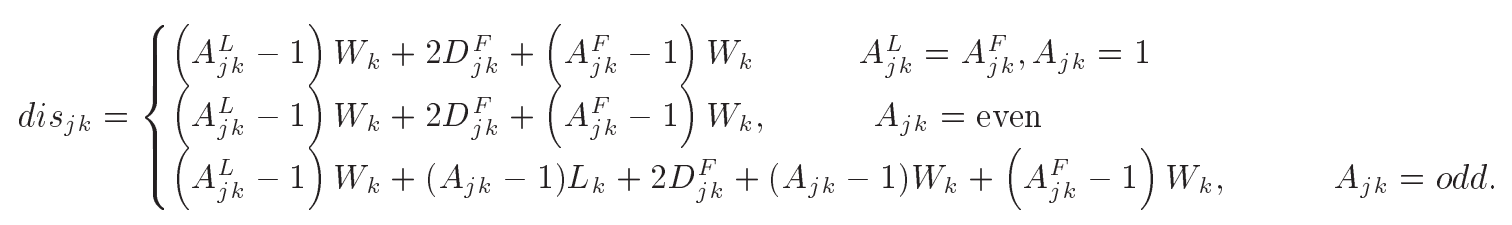

Box I

operator to each order batch, which is the sum of the operator moving time at a specific speed, the time of picking up of the goods from the shelf with the specified picking speed, and the launching time.

$$
\begin{aligned}
& T_{j k}^{\text {operator }}=\frac{d i s_{j k}}{v_{\text {travel }}}+\frac{y_{j k}}{v_{\text {pick }}}+t_{\text {setup }}, \\
& \forall j \in\{1, \ldots, m\}, \forall k \in\{1, \ldots, l\} .
\end{aligned}
$$

Eq. (16) calculates the time of shipment of the vehicle:

$$
T_{k}^{v e h}=\frac{x_{k}^{v e h}}{v_{v}(k)}, \quad \forall k \in\{1, \ldots, l\} .
$$

Eq. (17), shown in Box I, is the distance the operator of each block $k$ travels to collect the items of each order batch $j$ corresponding to that block.

Eq. (18) shows that listed variables are natural numbers, i.e. positive and integer:

$$
\begin{gathered}
y_{j k}, t_{j}^{\text {enter }}, t_{j}^{\text {batch }}, t_{j}^{T Q}, t_{j}^{\text {wait }}, t_{j}^{\text {start }}, T_{j}^{\text {service }}, T_{j k}^{\text {complete }}, \\
T_{j}^{\text {operator }}, T_{k}^{v e h}, I T_{j k}, T_{j}^{\text {response }} \geq 0 .
\end{gathered}
$$

Eq. (19) shows that $x_{i j}$ is binary:

$$
x_{i j}=0 \text { or } 1 \quad \forall i \in\{1, \ldots, n\}, \forall_{j \in\{1, \ldots, m\}} .
$$

The distance function $\left(d i s_{j k}\right)$ is derived from Zhang's research [18] and conforms to the s-shaped routing method $[14,49]$. In this study, the $A B C$ and ACO algorithms are used to solve the nonlinear model. In the next section, the corresponding real numerical example is analyzed, and then the results are presented.

\section{Experiment parameters}

\subsection{Purpose}

A series of experiments were considered in order to identify warehouse blocking performance. The purpose of these tests and experiments is to discuss turnover time in a number of blocks, and batching time per block $\left(t_{j}^{\text {batch }}\right)$ in upper bound time. Then results will be compared to those reported by Zhang et al. [18] All tests were performed on an Intel Core M processor with 8.0GB RAM. For simulation study MATLAB R2013b software is used to run the algorithm. Two case studies are considered and parameters, routing strategies, and Design Of Experiment (DOE) of each case are described in detail in each section.

\subsection{Parameters of Case Study 1}

The experiments are developed by defining a set of parameters including warehouse layout $A, P, L, L_{k}$, $W_{k}, v_{\text {travel }}, v_{\text {pick }}, t_{\text {setup }}, Q_{k}$, and $q_{i}$, which were introduced in Subsection 3.3 in Table 2. In addition, $t_{i}^{a}$ is used as the arrival time of the customer order, which is randomly valued according to the customer order quantity. The total number of ordered items are $n=120, n=240$, and $n=480$. Moreover, the warehouse values are given in Table 4 .

The routing strategy of the system is s-shaped, and the random-based storage policy has been formulated for the whole system. According to the following assumption, there are also several other effective parameters in this field: The ordered goods arrive during

Table 4. Parameters value of the experiment of Case Study 1.

\begin{tabular}{clll}
\hline Row & \multicolumn{1}{c}{ Parameter } & Symbol & \multicolumn{1}{c}{ Value } \\
\hline 1 & Total number of aisles & $A$ & 10 \\
2 & Number of pickers for a block & $P$ & 1 \\
3 & Number of storage locations & $L$ & 900 (90 storage locations have \\
& & & been placed on both sides of the aisle) \\
4 & Length of an aisles & $L_{k}$ & 45 meters \\
5 & Center-to-center distance between aisles & $W_{K}$ & 5 meters \\
6 & Travelling speed of picker & $v_{\text {travel }}$ & 48 meter per minute \\
7 & Pickup speed & $v_{\text {pick }}$ & 6 item per minute \\
8 & Setup time & $t_{\text {setup }}$ & 3 minutes \\
9 & Capacity of order picker vehicle & $Q_{k}$ & $30,45,60,75$ \\
10 & Constant distribution of number of goods for each order & $q_{i}$ & $\mathrm{q}_{\mathrm{i}} \sim \mathrm{U}(1,5)$ \\
\hline
\end{tabular}


Table 5. Parameter's value for statistical analysis of Case Study 2.

\begin{tabular}{clcc}
\hline Row & \multicolumn{1}{c}{ Parameter } & & Value \\
\hline 1 & Upper bound of the batching time & $T$ & $10,20,60$ \\
2 & Capacity of order picker vehicle & $Q_{k}$ & $30,45,60$ \\
3 & Number of customer orders & $n$ & $120,240,360$ \\
4 & Number of the warehouse blocks & $k$ & $2,4,6$ \\
\hline
\end{tabular}

4 hours and the inter-arrival times (the time in minutes between the arrival of customer order $i$ with $i+1$ ) are distributed exponentially and in proportion to the arrival rate $\lambda$, where $\lambda=0.5, \lambda=1$, or $\lambda=2$. The samples are generated by choosing different values for $\lambda, Q_{k}$ and $T$.

\subsection{Parameters of Case Study 2}

In Case Study 2, in order to better analyze the blocking effect, a small problem was developed and discussed in which the bottom warehouse involved 100 similar storage locations and 10 locations on both sides of the aisle. Each picker collects the orders from both the left and right sides of the aisle, simultaneously. The rest of the information used in this case, is exactly similar to the previous one. In Case Study 2, 23 scenarios are developed, in which four main parameters of the model i.e., $T, Q_{k}, n$, and $k$ are identified for sensitivity investigation. Also, three-parameter levels of high, average, and low are considered in order to examine these parameter's effects on target function. The parameter values are shown in Table 5 .

\subsection{Experimental results analysis}

4.4.1. Results of Case Study 1

In the first case study, the number of 36 problem categories as shown in Table 6, has been generated. 50 instance and finally, the total number of 1800 samples have been calculated for each problem. In this case study, response time extracted from the non-blocking model proposed by Zhang et al. [18] is compared with this model considering the blocking system. As can be seen from the table, $T^{\text {response }}, l^{\text {upper }}$, and $K^{\text {upper }}$ represent the response time of orders, the upper bound for picker number, and the upper bound for block number respectively. Table 6 also calculates and shows the improvement percentage of the presented model. Obviously, after applying a blocking system in a storage system, the trend of response time was much higher than that of a non-blocking system. The results obtained from the studies are compared with those of Ho and Tseng [19] research. It can be seen that the expected response time is reduced after the application of the blocking system. In addition, scenarios numbers 10 and 11 have a block that indicates data storage status similar to those without blocking. There is also a minimal improvement that shows that the blocking system with $\mathrm{ABC}$ and $\mathrm{ACO}$ algorithms is more efficient than the non-blocking system proposed by Zhang, in which the genetic algorithm is used. Regarding response time with the upper bound block number, it should be taken into account that a larger number of pickers will lead to better performance and efficiency, although this will certainly lead to higher wage costs.

\section{The $A B C$ algorithm}

The research results in Table 6 show that when $n=$ 120, $n=240$, and $n=480$, the following minimum response times with $\mathrm{ABC}$ algorithm are obtained under $T$ and $N$, respectively: $196.6649,204.8746,175.1411$, $195.9874, \quad 196.6079,215.1282,229.7651,228.2962$, 175.9501, 189.2771, 190.998, and 201.6838.

It can be seen that blocking leads to a reduction in response time. This type of decline is approximately $1.03 \%-26.54 \%$. For example when $n=120, Q_{k}=30$, $T=10$ (Scenario 1), and when there are two pickers in a warehouse that is in non-blocking mode, the order response time is expected to be 229.37. However, when the warehouse is divided into two blocks, the response time becomes 207.1348, indicating a reduction of approximately $9.69 \%$. Consequently, in most cases, increasing the number of blocks leads to a decrease in response time.

Table 7 shows an example of the best results for Scenario 1, in which orders are divided into 10 batches, including entry, waiting, start, service, completion, response, and idle times. According to obtained result, the average response time for this repetition is 207.2487, although the average response time for 10 repetitions is reported in Table 6 as 207.1348. The idle time of each picker is another parameter that has been investigated. According to statistics in Table 7, when there are 2 pickers for scenario number 1, the sum of idle times of almost all batch numbers remains almost unchanged. In fact, each picker in a batch should have a specific time to run the order batching system. Batch processing will not terminate unless each picker completes its task in each block. For example in a system with 2 blocks and pickers, each picker needs a specific time to accomplish their duties. When the last picker completes the task, the batch is completed, and the next batch starts. Thus the sum of picker idle time 
Table 6. The response time with upper bound block number, different capacities and various time intervals.

\begin{tabular}{|c|c|c|c|c|c|c|c|c|c|c|}
\hline \multirow{3}{*}{$\begin{array}{c}\text { Series } \\
\text { no. }\end{array}$} & \multirow[b]{3}{*}{$n$} & \multirow[b]{3}{*}{$Q_{k}$} & \multirow[b]{3}{*}{$T$} & \multicolumn{2}{|c|}{ No blocking [19] } & \multicolumn{5}{|c|}{$\begin{array}{r}\text { Blocking } \\
\end{array}$} \\
\hline & & & & \multirow[b]{2}{*}{$T^{\text {response }}$} & \multirow[b]{2}{*}{$l^{\text {upper }}$} & \multirow[b]{2}{*}{$\boldsymbol{K}^{\text {upper }}$} & \multicolumn{2}{|c|}{ ABC algorithm } & \multicolumn{2}{|c|}{ ACO algorithm } \\
\hline & & & & & & & $T^{\text {response }}$ & $\begin{array}{c}\text { Improvement } \\
\text { percentage }\end{array}$ & $T^{\text {response }}$ & $\begin{array}{c}\text { Improvement } \\
\text { percentage }\end{array}$ \\
\hline 1 & 120 & 30 & 10 & 229.37 & 2 & 2 & 207.1348 & 9.6940 & 196.8475 & 14.17 \\
\hline 2 & - & 30 & 20 & 238.62 & 2 & 2 & 211.9492 & 11.1771 & 204.4650 & 14.3135 \\
\hline 3 & - & 30 & 30 & 227.06 & 3 & 3 & 196.6649 & 13.3864 & 189.6013 & 16.4972 \\
\hline 4 & - & 45 & 15 & 230.55 & 2 & 2 & 218.4684 & 5.24 & 214.6384 & 6.90 \\
\hline 5 & - & 45 & 30 & 231.08 & 2 & 2 & 209.8094 & 9.20 & 198.9310 & 13.91 \\
\hline 6 & - & 45 & 45 & 246.39 & 2 & 2 & 204.8746 & 16.85 & 197.9802 & 19.65 \\
\hline 7 & - & 60 & 20 & 238.62 & 2 & 2 & 198.028 & 17.011 & 190.2251 & 20.28 \\
\hline 8 & - & 60 & 40 & 224.12 & 2 & 2 & 175.1411 & 21.8539 & 171.4753 & 23.49 \\
\hline 9 & - & 60 & 60 & 264.28 & 2 & 2 & 210.1725 & 20.47 & 204.2734 & 22.70 \\
\hline 10 & - & 75 & 25 & 243.66 & 1 & 1 & 241.1398 & 1.03 & 240.1629 & 1.43 \\
\hline 11 & - & 75 & 50 & 268.56 & 1 & 1 & 264.7907 & 1.40 & 262.5840 & 2.22 \\
\hline 12 & - & 75 & 75 & 251.77 & 2 & 2 & 195.9874 & 22.1562 & 191.1731 & 24.07 \\
\hline 13 & 240 & 30 & 5 & 258.74 & 4 & 4 & 234.8567 & 9.2306 & 229.6815 & 11.23 \\
\hline 14 & - & 30 & 10 & 258.15 & 4 & 4 & 216.9057 & 15.9769 & 211.0133 & 18.25 \\
\hline 15 & - & 30 & 15 & 259.15 & 5 & 5 & 196.6079 & 24.1336 & 190.2511 & 26.59 \\
\hline 16 & - & 45 & 7.5 & 260.89 & 3 & 3 & 250.3443 & 4.0422 & 250.1242 & 4.12 \\
\hline 17 & - & 45 & 15 & 261.75 & 3 & 3 & 215.1282 & 17.8116 & 218.4771 & 16.53 \\
\hline 18 & - & 45 & 22.5 & 269.2 & 3 & 3 & 234.9026 & 12.7405 & 217.8330 & 19.08 \\
\hline 19 & - & 60 & 10 & 260.67 & 2 & 2 & 250.8928 & 3.750 & 250.1285 & 4.044 \\
\hline 20 & - & 60 & 20 & 246.36 & 2 & 2 & 229.8074 & 6.7188 & 210.0428 & 14.74 \\
\hline 21 & - & 60 & 30 & 265.17 & 2 & 2 & 229.7651 & 13.3518 & 227.8410 & 14.07 \\
\hline 22 & - & 75 & 12.5 & 260.43 & 2 & 2 & 253.3516 & 2.7179 & 247.2745 & 5.051 \\
\hline 23 & - & 75 & 25 & 276.17 & 2 & 2 & 228.2962 & 24.5768 & 229.1821 & 17.01 \\
\hline 24 & - & 75 & 37.5 & 288.64 & 2 & 2 & 241.7122 & 16.2583 & 237.0395 & 17.87 \\
\hline 25 & 480 & 30 & 2.5 & 239.54 & 8 & 8 & 175.9501 & 26.54 & 190.9626 & 20.27 \\
\hline 26 & - & 30 & 5 & 245.18 & 7 & 7 & 208.8257 & 14.82 & 205.9912 & 15.98 \\
\hline 27 & - & 30 & 7.5 & 247.77 & 7 & 7 & 201.2619 & 18.77 & 199.8566 & 19.34 \\
\hline 28 & - & 45 & 3.75 & 244.77 & 6 & 6 & 189.2771 & 22.6714 & 177.2863 & 27.57 \\
\hline 29 & - & 45 & 7.5 & 247.7 & 5 & 5 & 201.3472 & 18.7133 & 200.8328 & 18.92 \\
\hline 30 & - & 45 & 11.25 & 246.61 & 5 & 5 & 204.5003 & 17.075 & 200.9098 & 18.53 \\
\hline 31 & - & 60 & 5 & 240.51 & 5 & 5 & 215.1638 & 10.5385 & 209.6521 & 12.83 \\
\hline 32 & - & 60 & 10 & 244.46 & 5 & 5 & 190.998 & 21.8694 & 190.677 & 22.00 \\
\hline 33 & - & 60 & 15 & 249.39 & 4 & 4 & 229.7128 & 7.8901 & 212.1236 & 14.94 \\
\hline 34 & - & 75 & 6.25 & 242.01 & 4 & 4 & 236.8028 & 2.1516 & 225.8842 & 6.66 \\
\hline 35 & - & 75 & 12.5 & 251.59 & 5 & 5 & 208.0244 & 17.3161 & 196.9139 & 21.73 \\
\hline 36 & - & 75 & 18.75 & 251.53 & 4 & 4 & 201.6838 & 19.8171 & 200.2188 & 20.40 \\
\hline
\end{tabular}

Table 7. The result of Artificial Bee-Colony (ABC) algorithm for scenario number 1.

\begin{tabular}{cccccccc}
\hline $\begin{array}{c}\text { Batch } \\
\text { no. }\end{array}$ & $\begin{array}{c}\text { Idle } \\
\text { time }\end{array}$ & $\begin{array}{c}\text { Batch } \\
\text { time }\end{array}$ & $\begin{array}{c}\text { Enter } \\
\text { time }\end{array}$ & $\begin{array}{c}\text { Wait } \\
\text { time }\end{array}$ & $\begin{array}{c}\text { Start } \\
\text { time }\end{array}$ & $\begin{array}{c}\text { Service } \\
\text { time }\end{array}$ & $\begin{array}{c}\text { Response } \\
\text { time }\end{array}$ \\
\hline 1 & {$[0 ; 1.1249]$} & 19.7679 & 32.9849 & 31.1303 & 64.1152 & 95.99001 & 160.1052 \\
2 & {$[0 ; 3.170]$} & 17.4446 & 18.0085 & 1.8918 & 19.9003 & 77.41685 & 97.3172 \\
3 & {$[0 ; 6.1203]$} & 18.1321 & 96.8961 & 51.243 & 148.139 & 101.60701 & 251.7461 \\
4 & {$[0 ; 0.1249]$} & 19.0508 & 94.2265 & 63.4094 & 137.636 & 21.90114 & 179.5371 \\
5 & {$[0 ; 0.853]$} & 18.5165 & 198.79 & 27.7285 & 226.518 & 12.16182 & 238.6802 \\
6 & {$[3.389 ; 0]$} & 19.0095 & 90.6824 & 20.2561 & 70.9386 & 61.2938 & 172.2324 \\
7 & {$[0.373 ; 0]$} & 11.9295 & 126.2408 & 90.0659 & 176.306 & 26.16701 & 242.4738 \\
8 & {$[0.360 ; 0]$} & 13.1276 & 135.654 & 64.4594 & 200.113 & 59.12892 & 259.2423 \\
9 & {$[0 ; 1.9583]$} & 0 & 151.3443 & 29.6288 & 180.973 & 45.54527 & 226.5184 \\
10 & {$[0 ; 0.9584]$} & 0 & 91.18621 & 148.4941 & 239.680 & 35.99001 & 244.6344 \\
\hline
\end{tabular}


Table 8. The result of Artificial Bee-Colony (ABC) algorithm for scenario number 3.

\begin{tabular}{cccccccc}
\hline $\begin{array}{c}\text { Batch } \\
\text { no. }\end{array}$ & $\begin{array}{c}\text { Idle } \\
\text { time }\end{array}$ & $\begin{array}{c}\text { Batch } \\
\text { time }\end{array}$ & $\begin{array}{c}\text { Enter } \\
\text { time }\end{array}$ & $\begin{array}{c}\text { Wait } \\
\text { time }\end{array}$ & $\begin{array}{c}\text { Start } \\
\text { time }\end{array}$ & $\begin{array}{c}\text { Service } \\
\text { time }\end{array}$ & $\begin{array}{c}\text { Response } \\
\text { time }\end{array}$ \\
\hline 1 & {$[1.0416 ; 0 ; 3.45833]$} & 29.127334 & 39.4037873 & 20.7524452 & 60.1562325 & 89.2494818 & 149.4057143 \\
2 & {$[1.0416 ; 0 ; 3.45853]$} & 29.72972 & 75.5786389 & 57.1891349 & 132.767774 & 68.3577506 & 201.125524 \\
3 & {$[0.0416 ; 0 ; 3.45833]$} & 29.78532 & 44.4982384 & 54.9074759 & 99.4057143 & 33.3620595 & 132.767774 \\
4 & {$[1.0416 ; 0 ; 3.45833]$} & 13.8452 & 13.9803715 & 0 & 13.9803715 & 86.1758609 & 100.1562325 \\
5 & {$[0.70839 ; 0 ; 2.9583]$} & 17.12197 & 136.894045 & 48.3355677 & 185.229612 & 89.9218081 & 275.151421 \\
6 & {$[1.04166 ; 0 ; 3.4583]$} & 24.53316 & 104.214899 & 56.9106253 & 161.125524 & 84.104088 & 245.229612 \\
7 & {$[0.541664 ; 0 ; 3.458]$} & 6.360553 & 179.579375 & 25.5720456 & 205.151421 & 16.0835369 & 221.234957 \\
8 & {$[0.541664 ; 0 ; 3.125]$} & 0 & 219.157743 & 2.07721447 & 221.234957 & 27.01267354 & 248.247631 \\
\hline
\end{tabular}

Table 9. The result of Ant-Colony (ACO) algorithm for scenario number 1.

\begin{tabular}{cccccccc}
\hline $\begin{array}{c}\text { Batch } \\
\text { no. }\end{array}$ & $\begin{array}{c}\text { Idle } \\
\text { time }\end{array}$ & $\begin{array}{c}\text { Batch } \\
\text { time }\end{array}$ & $\begin{array}{c}\text { Enter } \\
\text { time }\end{array}$ & $\begin{array}{c}\text { Wait } \\
\text { time }\end{array}$ & $\begin{array}{c}\text { Start } \\
\text { time }\end{array}$ & $\begin{array}{c}\text { Service } \\
\text { time }\end{array}$ & $\begin{array}{c}\text { Response } \\
\text { time }\end{array}$ \\
\hline 1 & {$[0.374099 ; 0]$} & 19.7980 & 31.38320 & 30.9341 & 62.3173 & 103.792 & 169.1093 \\
2 & {$[0.374999 ; 0]$} & 17.65466 & 17.85603 & 0 & 17.8561 & 44.4612 & 62.3173 \\
3 & {$[0.374999 ; 0]$} & 19.4208 & 96.07582 & 63.4615 & 159.5372 & 73.2089 & 232.74615 \\
4 & {$[0.374993 ; 0]$} & 19.1071 & 73.45186 & 58.78055 & 132.2325 & 77.3047 & 209.5372 \\
5 & {$[0.541667 ; 0]$} & 19.3368 & 179.2573 & 47.2611 & 196.5186 & 53.1617 & 249.6803 \\
6 & {$[0.374993 ; 0]$} & 19.1397 & 50.25339 & 49.8559 & 100.1093 & 62.1232 & 162.2325 \\
7 & {$[0.364293 ; 0]$} & 12.8575 & 80.6898 & 72.0563 & 152.74615 & 29.7323 & 182.4739 \\
8 & {$[0.376665 ; 0]$} & 13.0755 & 134.1049 & 68.3689 & 202.4739 & 56.7685 & 259.2424 \\
9 & {$[0 ; 1.958443]$} & 0 & 141.8242 & 67.4182 & 209.2424 & 17.2761 & 226.5185 \\
10 & {$[2.3750 ; 0]$} & 0 & 90.41424 & 19.2661 & 109.6803 & 104.9542 & 214.6345 \\
\hline
\end{tabular}

Table 10. The result of Ant-Colony (ACO) algorithm for scenario number 3.

\begin{tabular}{cccccccc}
\hline $\begin{array}{c}\text { Batch } \\
\text { no. }\end{array}$ & $\begin{array}{c}\text { Idle } \\
\text { time }\end{array}$ & $\begin{array}{c}\text { Batch } \\
\text { time }\end{array}$ & $\begin{array}{c}\text { Enter } \\
\text { time }\end{array}$ & $\begin{array}{c}\text { Wait } \\
\text { time }\end{array}$ & $\begin{array}{c}\text { Start } \\
\text { time }\end{array}$ & $\begin{array}{c}\text { Service } \\
\text { time }\end{array}$ & $\begin{array}{c}\text { Response } \\
\text { time }\end{array}$ \\
\hline 1 & {$[0.374999 ; 0 ; 0.098]$} & 19.79794 & 31.3832 & 30.9340 & 62.3172 & 77.9810 & 140.2982 \\
2 & {$[1.374999 ; 0 ; 0.115]$} & 17.65465 & 17.8560 & 0 & 17.8560 & 120.9611 & 128.8172 \\
3 & {$[0.374993 ; 0 ; 0.987]$} & 19.42086 & 96.0758 & 63.4613 & 159.5371 & 56.2090 & 215.7461 \\
4 & {$[1.374993 ; 0 ; 0.005]$} & 19.10708 & 73.4518 & 58.7805 & 132.2324 & 60.6047 & 192.8371 \\
5 & {$[0.541667 ; 0 ; 0.0067]$} & 19.33680 & 179.2573 & 47.2611 & 226.5184 & 43.1618 & 269.6803 \\
\hline
\end{tabular}

should be changed equally in each batch to obtain a reasonable result. Thus, in the best sample result, it is logical to adjust the average idle time to approximately 1.84 minutes. In the following Table 8 shows one of the best sample results for scenario number 3 and batch number 8 .

\section{The ACO algorithm}

Regarding the ACO algorithm, when $n=120, n=$ 240 , and $n=480$, the minimum response times under various $T$ and $N$ conditions are as following, respectively (Table 7): 189.6013, 197.9802, 171.4753, $191.1731, \quad 190.2511,217.8330,210.0428,229.1821$, 190.9626, 177.2863, 190.677, and 196.9139. It can be seen from Table 7 that similarly, in the ABC algorithm, blocking will result in a reduction in response time. This decline is approximately $1.43 \%$ -
$27.57 \%$. For example, in a non-blocking warehouse with two operators, when $n=120, Q_{k}=30$, orders response time will be 229.37 . When the warehouse is divided into 2 blocks, the order response time becomes 196.8475 , which shows a decrease of approximately $14.17 \%$. According to the results, scenario number 10 represents the lowest improvement in reducing response time, and scenario number 28 represents the highest improvement. Table 9 shows one of the best sample results for scenario number 1 , batch number 10 , and Table 10 shows one of the best sample results for scenario number 3 , and batch number 5 .

\subsubsection{Results of Case Study 2}

In the second case study, each scenario is repeated 10 times and the average results of the repetition in each scenario are shown in Tables 11-13. The result clearly 
Table 11. The result for scenarios numbers $1-27$.

\begin{tabular}{|c|c|c|c|c|c|c|c|c|}
\hline \multirow[b]{2}{*}{$\begin{array}{l}\text { Se. } \\
\text { no }\end{array}$} & \multirow[b]{2}{*}{$\begin{array}{c}\text { Number of } \\
\text { blocks }\end{array}$} & \multirow[b]{2}{*}{$\begin{array}{l}\text { Number of } \\
\text { orders } \\
\text { in } 4 \text { hour }\end{array}$} & \multirow[b]{2}{*}{$\boldsymbol{Q}_{K}$} & \multirow[b]{2}{*}{$T$} & \multicolumn{2}{|c|}{ ABC algorithm } & \multicolumn{2}{|c|}{ ACO algorithm } \\
\hline & & & & & $\begin{array}{l}\text { Response } \\
\text { time }\end{array}$ & $\begin{array}{c}\text { Mean of } \\
\text { idle times } \\
\text { (for per operator) }\end{array}$ & $\begin{array}{l}\text { Response } \\
\text { time }\end{array}$ & $\begin{array}{c}\text { Mean of } \\
\text { idle times } \\
\text { (for per operator) }\end{array}$ \\
\hline 1 & & & & 10 & 31.46586 & 0.625 & 26.46421 & 0.26 \\
\hline 2 & & & 30 & 20 & 32.59738 & 0.717 & 28.90588 & 0.42 \\
\hline 3 & & & & 60 & 34.97678 & 1.038 & 32.02254 & 0.368 \\
\hline 4 & & & & 10 & 26.88803 & 0.671 & 23.13921 & 0.48 \\
\hline 5 & & 120 & 45 & 20 & 34.8953 & 0.6415 & 30.58088 & 0.2056 \\
\hline 6 & & & & 60 & 28.65056 & 0.482 & 31.34754 & 0.217 \\
\hline 7 & & & & 10 & 34.9871 & 1.2515 & 29.3562 & 0.3417 \\
\hline 8 & & & 60 & 20 & 21.8313 & 0.4865 & 20.90588 & 0.4750 \\
\hline 9 & & & & 60 & 24.6595 & 0.625 & 32.02254 & 0.483 \\
\hline 10 & & & & 10 & 34.40607 & 3.9585 & 43.13921 & 0.3417 \\
\hline 11 & & & 30 & 20 & 35.22805 & 2.7085 & 37.58088 & 0.3283 \\
\hline 12 & & & & 60 & 32.1056 & 5.625 & 35.34754 & 0.4483 \\
\hline 13 & & & & 10 & 32.31897 & 5.607 & 26.46421 & 1.2883 \\
\hline 14 & 2 & 240 & 45 & 20 & 36.87066 & 1.0415 & 30.2547 & 0.1017 \\
\hline 15 & & & & 60 & 33.4589 & 5.2705 & 34.1235 & 0.1283 \\
\hline 16 & & & & 10 & 30.7990 & 1.0415 & 28.31 & 0.4217 \\
\hline 17 & & & 60 & 20 & 36.787 & 2.2915 & 29.0234 & 0.21 \\
\hline 18 & & & & 60 & 50.86018 & 0.628 & 42.145 & 0.187 \\
\hline 19 & & & & 10 & 67.6630 & 1.0415 & 59.328 & 0.0903 \\
\hline 20 & & & 30 & 20 & 52.9769 & 2.2915 & 52.1236 & 0.235 \\
\hline 21 & & & & 60 & 43.803 & 2.7085 & 40.18 & 0.1384 \\
\hline 22 & & & & 10 & 52.7657 & 3.9585 & 48.045 & 0.1263 \\
\hline 23 & & 360 & 45 & 20 & 46.71353 & 2.7095 & 43.2736 & 0.3957 \\
\hline 24 & & & & 60 & 41.98127 & 1.0415 & 38.3307 & 0.2312 \\
\hline 25 & & & & 10 & 46.71353 & 2.7085 & 43.0087 & 0.3417 \\
\hline 26 & & & 60 & 20 & 41.98127 & 1.0415 & 40.18 & 0.3683 \\
\hline 27 & & & & 60 & 44.3746 & 2.7085 & 39.468 & 0.7350 \\
\hline
\end{tabular}

shows the effects of blocking on reducing response time. For example, in the three scenarios including numbers 1,28 , and 55, the response time of both $\mathrm{ABC}$ and ACO algorithms is decreased by increasing the number of blocks with the same three-parameter values of $T$, $n, Q_{k}$ equal to 10,120 , and 30 respectively. It is worth noting that in these three scenarios, the response time and average idle times for the ACO algorithm were lower than the $\mathrm{ABC}$ algorithm. Compared to other scenarios, the ACO algorithm showed a better performance. Conversely, the average idle time of each picker increased. However, the average increase in idle time was insignificant compared to the reduction in the response time level shown in Figure 3.

\subsection{Design Of Experiment (DOE) for analyzing the research results}

4.5.1. DOE of Case Study 1

The $A B C$ algorithm

The two assumptions of $\mathrm{H} 0$ and $\mathrm{H} 1$, when comparing 
Table 12. The result for scenarios no. $28-54$.

\begin{tabular}{|c|c|c|c|c|c|c|c|c|}
\hline \multirow[b]{2}{*}{$\begin{array}{l}\text { Se. } \\
\text { no }\end{array}$} & \multirow[b]{2}{*}{$\begin{array}{c}\text { Number of } \\
\text { blocks }\end{array}$} & \multirow[b]{2}{*}{$\begin{array}{l}\text { Number of } \\
\text { orders } \\
\text { in } 4 \text { hour }\end{array}$} & \multirow[b]{2}{*}{$Q_{K}$} & \multirow[b]{2}{*}{$T$} & \multicolumn{2}{|c|}{ ABC algorithm } & \multicolumn{2}{|c|}{ ACO algorithm } \\
\hline & & & & & $\begin{array}{c}\text { Response } \\
\text { time }\end{array}$ & $\begin{array}{c}\text { Mean of } \\
\text { idle times } \\
\text { (for per operator) }\end{array}$ & $\begin{array}{l}\text { Response } \\
\text { time }\end{array}$ & $\begin{array}{c}\text { Mean of } \\
\text { idle times } \\
\text { (for per operator) }\end{array}$ \\
\hline 28 & & & & 10 & 28.6257 & 4.0275 & 24.6651 & 1.03808 \\
\hline 29 & & & 30 & 20 & 26.78054 & 5.972 & 22.13 & 1.2204 \\
\hline 30 & & & & 60 & 26.5773 & 4.0275 & 19.28 & 1.28 \\
\hline 31 & & & & 10 & 23.12815 & 5.1385 & 20.1269 & 1.3675 \\
\hline 32 & & 120 & 45 & 20 & 22.1472 & 4.861 & 21.7419 & 1.1592 \\
\hline 33 & & & & 60 & 23.42084 & 2.6385 & 17.8095 & 1.1806 \\
\hline 34 & & & & 10 & 23.17927 & 3.3335 & 18.4867 & 1.300 \\
\hline 35 & & & 60 & 20 & 20.2773 & 3.9585 & 19.8810 & 1.2105 \\
\hline 36 & & & & 60 & 26.7017 & 3.5415 & 18.4992 & 1.4075 \\
\hline 37 & & & & 10 & 37.3493 & 3.9585 & 32.0070 & 1.4206 \\
\hline 38 & & & 30 & 20 & 38.9842 & 4.0285 & 31.9859 & 1.3944 \\
\hline 39 & & & & 60 & 38.3076 & 5.2085 & 30.3012 & 1.2792 \\
\hline 40 & & & & 10 & 35.48914 & 4.935 & 25.7882 & 1.3275 \\
\hline 41 & 4 & 240 & 45 & 20 & 30.1120 & 3.3335 & 21.6634 & 1.2342 \\
\hline 42 & & & & 60 & 28.9145 & 4.375 & 25.7635 & 1.3058 \\
\hline 43 & & & & 10 & 28.0672 & 6.0415 & 23.9582 & 1.2614 \\
\hline 44 & & & 60 & 20 & 24.1576 & 3.3335 & 23.9980 & 1.2075 \\
\hline 45 & & & & 60 & 31.2005 & 4.375 & 24.1346 & 1.4057 \\
\hline 46 & & & & 10 & 52.4328 & 6.0415 & 43.5150 & 1.2743 \\
\hline 47 & & & 30 & 20 & 61.9593 & 6.875 & 39.8497 & 1.2319 \\
\hline 48 & & & & 60 & 53.8346 & 4.375 & 34.2031 & 1.3140 \\
\hline 49 & & & & 10 & 43.83187 & 4.1665 & 35.7983 & 1.3927 \\
\hline 50 & & 360 & 45 & 20 & 34.4335 & 2.875 & 33.0984 & 1.2794 \\
\hline 51 & & & & 60 & 39.76728 & 4.2085 & 31.3467 & 1.1683 \\
\hline 52 & & & & 10 & 36.4128 & 1.875 & 29.6005 & 1.2118 \\
\hline 53 & & & 60 & 20 & 34.8676 & 4.375 & 26.3298 & 1.1675 \\
\hline 54 & & & & 60 & 27.3302 & 4.4415 & 23.2455 & 0.9967 \\
\hline
\end{tabular}

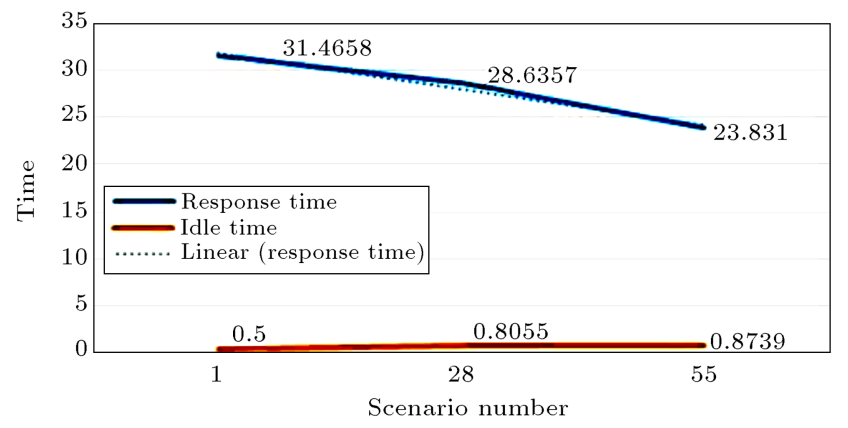

Figure 3. Average increased level of idle time and decrease level of order response time for the three scenario.

the results of the $\mathrm{ABC}$ algorithm with the non-blocking results in the first case study, are considered as follows:

H0: There is no significant difference between the two samples;
H1: There is a significant difference between the two samples.

To test this hypothesis, paired T-test is used. This test is used when the same sample is tested in two different circumstances. Compared with other tests, one of the advantages of the T-test is that it allows us to easily identify the differences. As seen in Table 14, the average response time in the non-blocking mode was 250.2906, while in blocking mode using ABC method, it dropped to 216.1189. Table 15, shows the correlation between two groups with the value of 0.57. It is indicated that there is significant correlation between the two models. Table 16, shows the mean test results of the difference between the blocking and non-blocking methods and the average response time in terms of the average response time. This table shows that the reduction in the average response time 
Table 13. The result for scenarios no. $55-81$.

\begin{tabular}{|c|c|c|c|c|c|c|c|c|}
\hline \multirow[b]{2}{*}{$\begin{array}{l}\text { Se. } \\
\text { no }\end{array}$} & \multirow[b]{2}{*}{$\begin{array}{c}\text { Number of } \\
\text { blocks }\end{array}$} & \multirow[b]{2}{*}{$\begin{array}{l}\text { Number of } \\
\text { orders } \\
\text { in } 4 \text { hour }\end{array}$} & \multirow[b]{2}{*}{$\boldsymbol{Q}_{K}$} & \multirow[b]{2}{*}{$T$} & \multicolumn{2}{|c|}{ ABC algorithm } & \multicolumn{2}{|c|}{ ACO algorithm } \\
\hline & & & & & $\begin{array}{l}\text { Response } \\
\text { time }\end{array}$ & $\begin{array}{c}\text { Mean of } \\
\text { idle times } \\
\text { (for per operator) }\end{array}$ & $\begin{array}{l}\text { Response } \\
\text { time }\end{array}$ & $\begin{array}{c}\text { Mean of } \\
\text { idle times } \\
\text { (for per operator) }\end{array}$ \\
\hline 55 & \multirow{27}{*}{6} & \multirow{9}{*}{120} & \multirow{3}{*}{30} & 10 & 23.8310 & 4.8695 & 17.1011 & 3.8038 \\
\hline 56 & & & & 20 & 19.7756 & 5.46875 & 19.4604 & 5.2153 \\
\hline 57 & & & & 60 & 26.9153 & 5.625 & 14.9024 & 4.3217 \\
\hline 58 & & & \multirow{3}{*}{45} & 10 & 21.4276 & 3.3335 & 20.2223 & 3.0062 \\
\hline 59 & & & & 20 & 17.3798 & 3.0415 & 21.9404 & 2.3657 \\
\hline 60 & & & & 60 & 22.8120 & 2.625 & 22.0712 & 2.1850 \\
\hline 61 & & & \multirow{3}{*}{60} & 10 & 18.4095 & 3.0805 & 16.0344 & 2.9654 \\
\hline 62 & & & & 20 & 14.6472 & 4.375 & 14.1159 & 4.1091 \\
\hline 63 & & & & 60 & 28.8574 & 3.368 & 25.7489 & 3.2074 \\
\hline 64 & & \multirow{9}{*}{240} & \multirow{3}{*}{30} & 10 & 36.6023 & 2.625 & 28.254 & 3.3114 \\
\hline 65 & & & & 20 & 33.97472 & 3.79 & 34.064 & 3.009 \\
\hline 66 & & & & 60 & 37.98916 & 3.374 & 33.1256 & 2.9804 \\
\hline 67 & & & \multirow{3}{*}{45} & 10 & 28.4896 & 3.3625 & 25.0765 & 2.8037 \\
\hline 68 & & & & 20 & 28.02358 & 3.624 & 26.6843 & 3.2742 \\
\hline 69 & & & & 60 & 30.06142 & 5.06 & 29.1872 & 4.9040 \\
\hline 70 & & & \multirow{3}{*}{60} & 10 & 27.5935 & 2.0305 & 25.554 & 1.9056 \\
\hline 71 & & & & 20 & 18.3930 & 2.625 & 22.1423 & 2.1083 \\
\hline 72 & & & & 60 & 29.7453 & 3.995 & 23.4217 & 2.4450 \\
\hline 73 & & \multirow{9}{*}{360} & \multirow{3}{*}{30} & 10 & 50.3123 & 4.6245 & 42.1438 & 3.8128 \\
\hline 74 & & & & 20 & 48.4042 & 2.375 & 40.1851 & 1.9453 \\
\hline 75 & & & & 60 & 51.5352 & 3.3395 & 50.0137 & 3.0927 \\
\hline 76 & & & \multirow{3}{*}{45} & 10 & 34.7184 & 4.2185 & 30.1283 & 3.7124 \\
\hline 77 & & & & 20 & 36.7643 & 3.1 & 30.9873 & 2.583 \\
\hline 78 & & & & 60 & 37.5417 & 2.625 & 34.1760 & 2.1821 \\
\hline 79 & & & \multirow{3}{*}{60} & 10 & 32.7923 & 4.1155 & 28.4354 & 3.0109 \\
\hline 80 & & & & 20 & 29.79935 & 4.507 & 27.0961 & 3.3426 \\
\hline 81 & & & & 60 & 34.3214 & 4.625 & 33.4357 & 3.836 \\
\hline
\end{tabular}

Table 14. Paired samples statistics for Artificial Bee-Colony (ABC) algorithm and non-blocking results.

\begin{tabular}{lccccc}
\hline \multicolumn{5}{c}{ Paired samples statistics } \\
\hline \multirow{4}{*}{ Pair 1 } & Mean & $\boldsymbol{N}$ & Std. deviation & Std. error mean \\
\cline { 3 - 6 } & & 250.2906 & 36 & 14.22869 & 2.37145 \\
& ABC & 216.1189 & 36 & 21.7781 & 3.6296 \\
\hline
\end{tabular}

Table 15. Paired samples correlations for Artificial Bee-Colony (ABC) algorithm and non-blocking results.

\begin{tabular}{ccccc}
\hline \multicolumn{4}{c}{ Paired samples correlations } \\
\hline & & $\boldsymbol{N}$ & Correlation & Sig. \\
\hline Pair 1 & Non-blocking \& ABC & 36 & 0.578 & 0.000 \\
\hline
\end{tabular}

Table 16. Paired samples test for Artificial Bee-Colony (ABC) and non-blocking results.

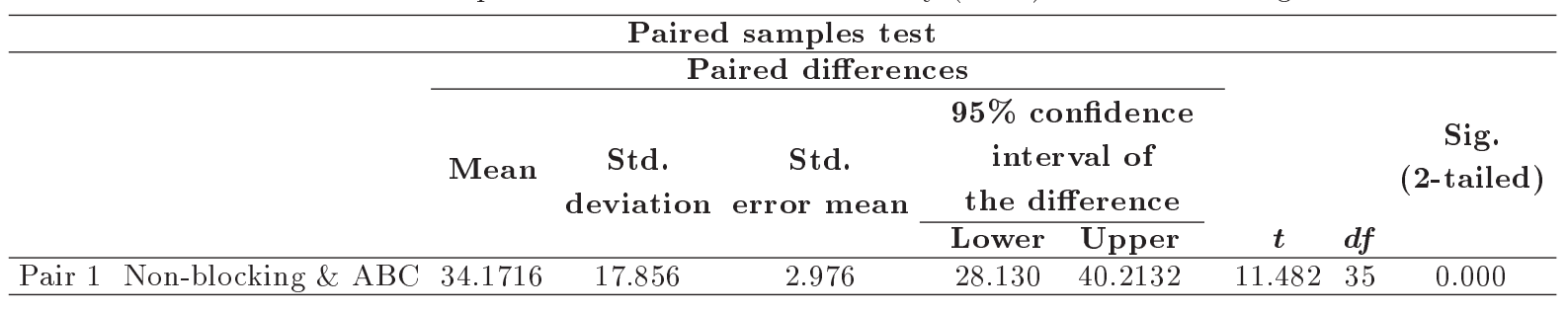


Table 17. Paired samples statistics for Ant-Colony (ACO) algorithm and non-blocking results.

\begin{tabular}{cccccc}
\hline \multicolumn{5}{c}{ Paired samples correlations } \\
\hline & Mean & $\boldsymbol{N}$ & Std. deviation & Std. error mean \\
\hline \multirow{2}{*}{ Pair 1 } & Non-blocking & 250.2906 & 36 & 14.22869 & 2.37145 \\
& ACO & 210.904 & 36 & 21.6268 & 3.6044 \\
\hline
\end{tabular}

Table 18. Paired samples correlations for Ant-Colony (ACO) algorithm and non-blocking results.

\begin{tabular}{ccccc}
\hline \multicolumn{5}{c}{ Paired samples correlations. } \\
\hline & $\boldsymbol{N}$ & Correlation & Sig. \\
\hline Pair 1 & Non-blocking \& ACO & 36 & 0.611 & 0.000 \\
\hline
\end{tabular}

Table 19. Paired Samples test for Ant-Colony (ACO) algorithm and non-blocking results.

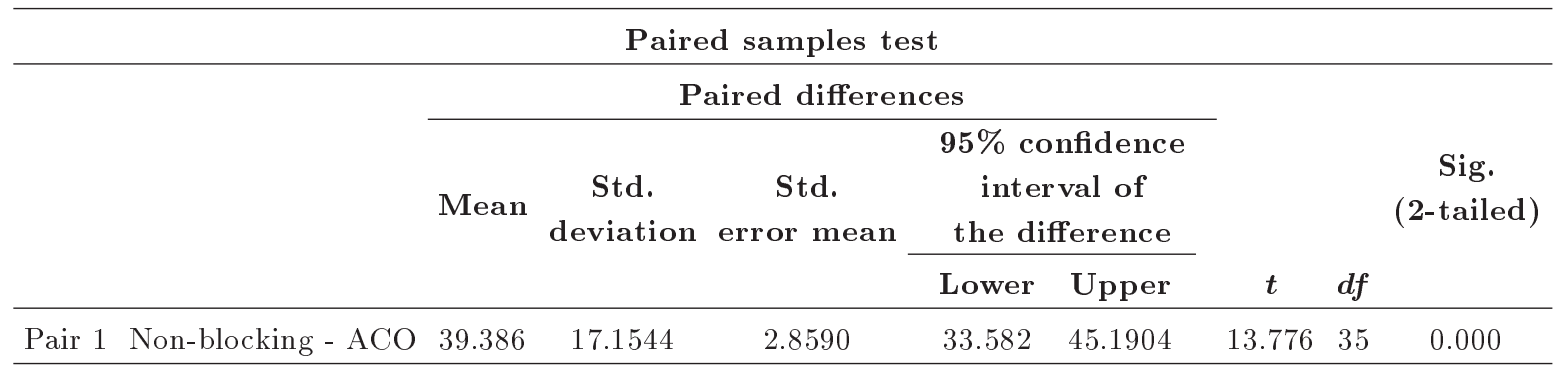

Table 20. Paired samples statistics for Artificial Bee-Colony (ABC) and Ant-Colony (ACO) algorithms results.

\begin{tabular}{cccccc}
\hline & & Mean & $\boldsymbol{N}$ & Std. deviation & Std. error mean \\
\hline \multirow{2}{*}{ Pair 1 } & ABC & 216.1188 & 36 & 21.7781 & 3.6296 \\
& ACO & 210.9042 & 36 & 21.6268 & 3.6044 \\
\hline
\end{tabular}

Table 21. Paired samples correlations for Artificial Bee-Colony (ABC) and Ant-Colony (ACO) algorithms results.

\begin{tabular}{ccccc}
\hline \multicolumn{4}{c}{ Paired samples correlations } \\
\hline & & $\boldsymbol{N}$ & Correlation & Sig. \\
\cline { 3 - 5 } Pair 1 & ACO \& ABC & 36 & 0.958 & 0.000 \\
\hline
\end{tabular}

in the blocking method is significant due to obtained significance amount of zero which is less than 0.05 . The correlation coefficient was 0.578 , so there is a significant correlation between the two models.

\section{The ACO algorithm}

To examine the results obtained from the ACO algorithm with non-blocking results, we consider the following assumptions:

H0: There is no significant difference between the results of the two methods;

H1: There is a significant difference between the results of the two methods.

As is clear from Tables 17-19, the average score in nonblocking was 250.2906 , which reduced to 210.904 using the ACO method. Because the significance level of 0.0 is less than 0.05 , this value is statistically significant. The correlation coefficient was 0.611 , indicating the significant correlation between the results of the two methods.

\section{Comparison of the results of the $A C O$ algorithm with the $A B C$ algorithm}

To examine the results of the ACO with the ABC solution method, we considered the following assumptions in Case Study 1:

H0: There is no significant difference between the results of the two methods;

H1: There is a significant difference between the results of the two methods.

As shown in Tables 20-22, the average ABC score was 216.1188, which dropped to 210.9042 in the ACO 
Table 22. Paired samples test for Artificial Bee-Colony (ABC) and Ant-Colony (ACO) algorithms results.

\begin{tabular}{|c|c|c|c|c|c|c|c|c|c|}
\hline \multicolumn{10}{|c|}{ Paired samples test } \\
\hline & & \multicolumn{5}{|c|}{ Paired differences } & & & \multirow{3}{*}{$\begin{array}{c}\text { Sig. } \\
(2-\text { tailed })\end{array}$} \\
\hline & & \multirow[t]{2}{*}{ Mean } & \multirow[t]{2}{*}{$\begin{array}{c}\text { Std. } \\
\text { deviation }\end{array}$} & \multirow[t]{2}{*}{$\begin{array}{l}\text { Std. } \\
\text { error mean }\end{array}$} & \multicolumn{2}{|c|}{$\begin{array}{c}95 \% \text { confidence } \\
\text { interval of } \\
\text { the difference }\end{array}$} & \multirow[b]{2}{*}{$t$} & \multirow[b]{2}{*}{$d f$} & \\
\hline & & & & & Lower & Upper & & & \\
\hline Pair 1 & $\mathrm{ACO} \& \mathrm{ABC}$ & 5.2145 & 6.2962 & 1.0493 & 3.0842 & 7.344 & 4.969 & 35 & 0.000 \\
\hline
\end{tabular}

Table 23. The ANOVA analysis to the impact parameter recognition of $k, n, Q_{k}$, and $T$ on response time for Artificial Bee-Colony (ABC) algorithm.

\begin{tabular}{cccccc}
\hline \multicolumn{5}{c}{ ANOVA } \\
\hline & Sum of squares & $\boldsymbol{d} \boldsymbol{f}$ & Mean square & Sum of squares \\
\hline Parameter $\boldsymbol{k}$ & & & & & \\
Between groups & 1006.083 & 2 & 503.042 & 4.223 & 0.018 \\
Within groups & 9291.093 & 78 & 119.117 & - & - \\
Total & 10297.177 & 80 & - & - & - \\
Parameter $\boldsymbol{n}$ & & & & & \\
Between groups & 4751.698 & 2 & 2375.849 & 33.418 & -000 \\
Within groups & 5545.478 & 78 & 71.096 & - & - \\
Total & 10297.177 & 80 & - & - & - \\
Parameter $\boldsymbol{Q} \boldsymbol{k}$ & & & & - & - \\
Between groups & 1151.647 & 2 & 575.824 & 4.911 & - \\
Within groups & 9145.530 & 78 & 117.250 & - & - \\
Total & 10297.177 & 80 & - & - & - \\
Parameter $\boldsymbol{T}$ & & & & - & - \\
Between groups & 122.530 & 2 & 61.265 & 0.470 & - \\
Within groups & 10174.647 & 78 & 130.444 & - & - \\
Total & 10297.177 & 80 & - & - & - \\
\hline
\end{tabular}

algorithm. Because the significance level of 0.0 is less than 0.05 , this value is statistically significant. The correlation coefficient is calculated to be 0.958 , so there is a significant correlation between the two groups. It is worth noting that by comparing the results of the average score of the ACO and ABC methods, it can be said that the improvement of the ACO method was more than that of the ABC method.

\subsubsection{DOE of Case Study 2}

By assuming $\mathrm{H} 0$ and $\mathrm{H} 1$ which represent the effect of three levels (Table 5) of 4 parameters of $k, n, Q_{k}$, and $T$ in the ABC and ACO algorithms, the second case study will be obtained as below:

H0: There is no significant difference between the obtained results of three levels of $k, n, Q_{k}$, and $T$;

H1: There is a significant difference between the obtained results of three levels of $k, n, Q_{k}$, and $T$.
It is necessary to adjust the input parameters of the algorithms to improve the solution proposed by the algorithm function. The ANOVA test results for response times of Case Study 2 are presented in Tables 23 and 24. This is mainly used to identify the optimization level of each parameter. According to these results, parameters $k, n$, and $Q_{k}$ are categorized as effective parameters. For example, for parameter $k$, the significance value of the ABC algorithm was 0.018, and the significance value of the ACO algorithm was 0.0 , both of which are less than 0.05 and are categorized as the effective parameters. In addition, it is mentioned that the parameter $T$ did not have a significant level of the obtained results. It is noteworthy that the parameter effectiveness could be investigated by changing the amount of these values.

In the following, the Tamhane test is used to determine the optimal values of the parameters defined in Table 5, and the results are presented in Tables 25 and 26. The values of the optimal parameters are 
Table 24. The ANOVA analysis to the impact parameter recognition of $k, n, Q_{k}$, and $T$ on response time for Ant-Colony (ACO) algorithm.

\begin{tabular}{cccccc}
\hline & Sum of squares & $\boldsymbol{d} \boldsymbol{f}$ & Mean square & $\boldsymbol{F}$ & Sig. \\
\hline Parameter $\boldsymbol{k}$ & & & & & \\
Between groups & 1401.696 & 2 & 700.848 & 10.588 & 0.000 \\
Within groups & 5163.229 & 78 & 66.195 & - & - \\
Total & 6564.925 & 80 & - & - & - \\
Parameter $\boldsymbol{n}$ & & & & & \\
Between groups & 3100.484 & 2 & 1550.242 & 34.903 & 0.000 \\
Within groups & 3464.441 & 78 & 44.416 & - & - \\
Total & 6564.925 & 80 & & & \\
Parameter $\boldsymbol{Q} \boldsymbol{k}$ & & & & & \\
Between groups & 665.923 & 2 & 332.961 & 4.403 & 0.015 \\
Within groups & 5899.002 & 78 & 75.628 & - & - \\
Total & 6564.925 & 80 & - & - & - \\
Parameter $\boldsymbol{T}$ & & & & & \\
Between groups & 14.878 & 2 & 7.439 & 0.089 & 0.915 \\
Within groups & 6550.047 & 78 & 83.975 & - & - \\
Total & 6564.925 & 80 & - & - & - \\
\hline
\end{tabular}

Table 25. Tamhane test to determine the optimal values of the parameter $k, n, Q_{k}$ and $T$ time for Artificial Bee-Colony (ABC) algorithm. Dependent variable: response time.

\begin{tabular}{|c|c|c|c|c|c|c|}
\hline \multirow{2}{*}{$(I) K$} & \multirow{2}{*}{$(J) K$} & \multirow{2}{*}{$\begin{array}{l}\text { Mean difference } \\
\qquad(I-J)\end{array}$} & \multirow{2}{*}{ Std. error } & \multirow{2}{*}{ Sig. } & \multicolumn{2}{|c|}{$95 \%$ confidence interval } \\
\hline & & & & & Lower bound & Upper bound \\
\hline \multicolumn{7}{|c|}{ Parameter $k$} \\
\hline \multirow{2}{*}{2} & 4 & 5.35070556 & 2.97042932 & .176 & -1.7464247 & 12.4478358 \\
\hline & 6 & $8.54229296^{*}$ & 2.97042932 & .014 & 1.4451627 & 15.6394232 \\
\hline \multirow{2}{*}{4} & 2 & -5.35070556 & 2.97042932 & .176 & -12.4478358 & 1.7464247 \\
\hline & 6 & 3.19158741 & 2.97042932 & .533 & -3.9055429 & 10.2887177 \\
\hline \multirow{2}{*}{6} & 2 & $-8.54229296^{*}$ & 2.97042932 & .014 & -15.6394232 & -1.4451627 \\
\hline & 4 & -3.19158741 & 2.97042932 & .533 & -10.2887177 & 3.9055429 \\
\hline \multicolumn{7}{|c|}{ Parameter $n$} \\
\hline \multirow{2}{*}{120} & 240 & $-8.16458667^{*}$ & 1.99260128 & .001 & -13.1150358 & -3.2141375 \\
\hline & 360 & $-18.71061815^{*}$ & 2.23687222 & .000 & -24.2893430 & -13.1318933 \\
\hline \multirow{2}{*}{240} & 120 & $8.16458667^{*}$ & 1.99260128 & .001 & 3.2141375 & 13.1150358 \\
\hline & 360 & $-10.54603148^{*}$ & 2.61247511 & .001 & -16.9961273 & -4.0959357 \\
\hline \multirow{2}{*}{360} & 120 & $18.71061815^{*}$ & 2.23687222 & .000 & 13.1318933 & 24.2893430 \\
\hline & 240 & $10.54603148^{*}$ & 2.61247511 & .001 & 4.0959357 & 16.9961273 \\
\hline \multicolumn{7}{|c|}{ Parameter $Q_{k}$} \\
\hline \multirow{2}{*}{30} & 45 & 7.31140593 & 2.94706859 & .052 & -.0430417 & 14.6658535 \\
\hline & 60 & $8.54322815^{* *}$ & 2.94706859 & .018 & 1.1887805 & 15.8976758 \\
\hline \multirow{2}{*}{45} & 30 & -7.31140593 & 2.94706859 & .052 & -14.6658535 & .0430417 \\
\hline & 60 & 1.23182222 & 2.94706859 & .916 & -6.1226254 & 8.5862698 \\
\hline \multirow{2}{*}{60} & 30 & $-8.54322815^{*}$ & 2.94706859 & .018 & -15.8976758 & -1.1887805 \\
\hline & 45 & -1.23182222 & 2.94706859 & .916 & -8.5862698 & 6.1226254 \\
\hline
\end{tabular}

*The mean difference is significant at the 0.05 level. 

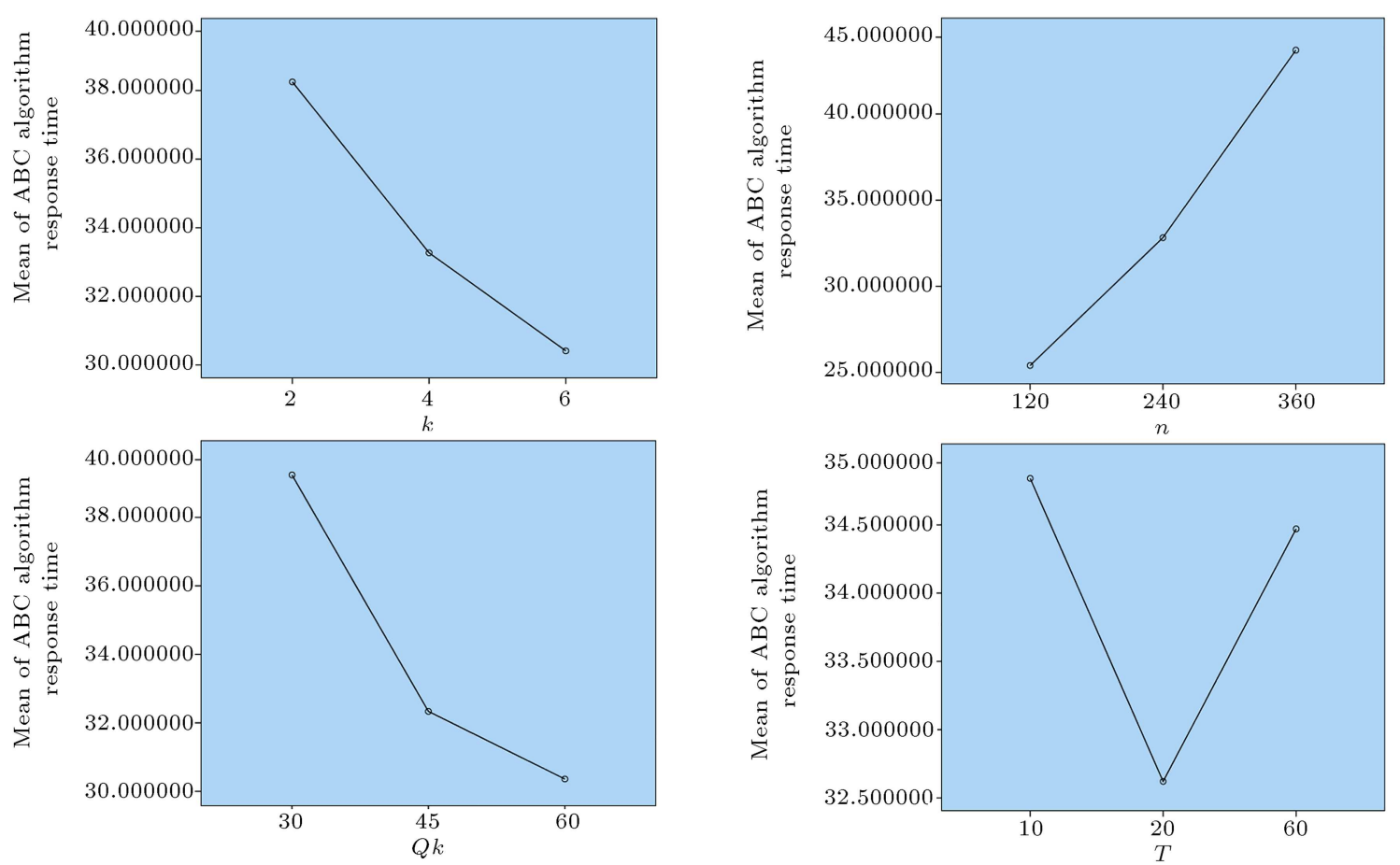

Figure 4. Change of response time by changing the value of parameters $k, n, Q_{k}$, and $T$ for Artificial Bee-Colony (ABC) algorithm.
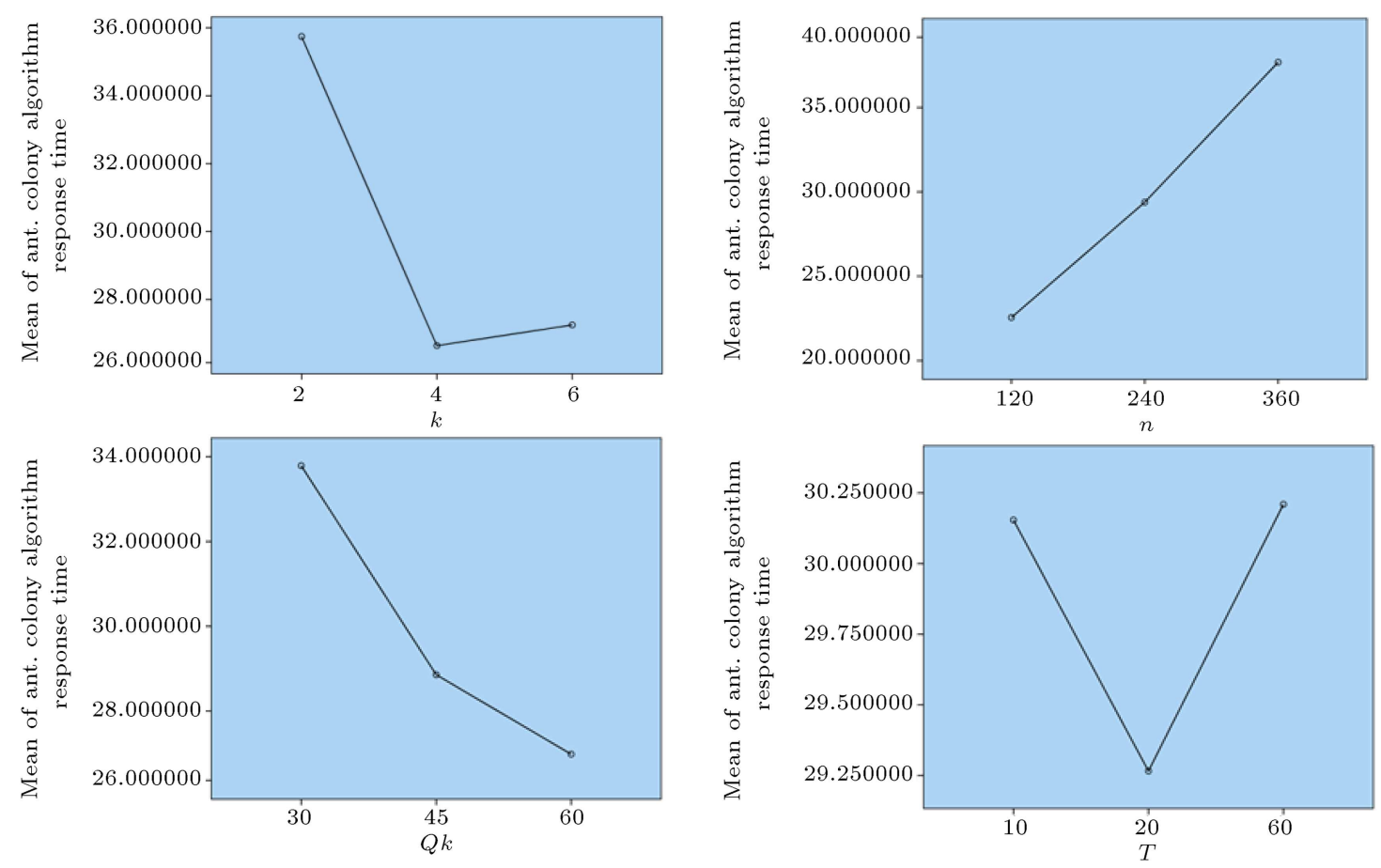

Figure 5. Change of response time by changing the value of parameters $k, n, Q_{k}, T$ for Ant-Colony (ACO) algorithm.

specified based on the results shown in Figures 4 and 5 . The values of the optimal parameters have been presented in Table 27.

\section{Summary and future works}

Throughput time of arbitrary order is called an order picking system. With the increase in order picking speed, the delivery time is shortened, and the quality of warehouse service is improved. Order picking area and order batching are the two most important factors to improve order picking efficiency. The current research aims to study online order batch processing using warehouse blocking systems in pick-to-parts and 
Table 26. Tamhane test to determine the optimal values of the parameter $k, n, Q_{k}$ and $T$ for Ant-Colony (ACO) algorithm. Dependent variable: response time.

\begin{tabular}{|c|c|c|c|c|c|c|}
\hline \multirow{2}{*}{$(I) K$} & \multirow{2}{*}{$(\boldsymbol{J}) \boldsymbol{K}$} & \multirow{2}{*}{$\begin{array}{l}\text { Mean difference } \\
\qquad(I-J)\end{array}$} & \multirow{2}{*}{ Std. error } & \multirow{2}{*}{ Sig. } & \multicolumn{2}{|c|}{$95 \%$ confidence interval } \\
\hline & & & & & Lower bound & Upper bound \\
\hline \multicolumn{7}{|c|}{ Parameter $k$} \\
\hline \multirow{2}{*}{2} & 4 & $9.11419333^{*}$ & 2.21435118 & .000 & 3.5882515 & 14.6401352 \\
\hline & 6 & $8.50305630 *$ & 2.21435118 & .001 & 2.9771144 & 14.0289982 \\
\hline \multirow{2}{*}{4} & 2 & $-9.11419333^{*}$ & 2.21435118 & .000 & -14.6401352 & -3.5882515 \\
\hline & 6 & -.61113704 & 2.21435118 & .963 & -6.1370789 & 4.9148048 \\
\hline \multirow{2}{*}{6} & 2 & $-8.50305630^{*}$ & 2.21435118 & .001 & -14.0289982 & -2.9771144 \\
\hline & 4 & .61113704 & 2.21435118 & .963 & -4.9148048 & 6.1370789 \\
\hline \multicolumn{7}{|c|}{ Parameter $n$} \\
\hline \multirow{2}{*}{120} & 240 & $-6.84212815^{*}$ & 1.49933021 & .000 & -10.5416043 & -3.1426520 \\
\hline & 360 & $-15.13166000^{*}$ & 1.93367942 & .000 & -19.9326440 & -10.3306760 \\
\hline \multirow{2}{*}{240} & 120 & $6.84212815^{*}$ & 1.49933021 & .000 & 3.1426520 & 10.5416043 \\
\hline & 360 & $-8.28953185^{*}$ & 1.97055692 & .000 & -13.1749446 & -3.4041191 \\
\hline \multirow{2}{*}{360} & 120 & $15.13166000^{*}$ & 1.93367942 & .000 & 10.3306760 & 19.9326440 \\
\hline & 240 & $8.28953185^{*}$ & 1.97055692 & .000 & 3.4041191 & 13.1749446 \\
\hline \multicolumn{7}{|c|}{ Parameter $Q_{k}$} \\
\hline \multirow{2}{*}{30} & 45 & 4.92997481 & 2.36687369 & .121 & -.9765890 & 10.8365386 \\
\hline & 60 & $6.79710148^{*}$ & 2.36687369 & .020 & .8905377 & 12.7036653 \\
\hline \multirow{2}{*}{45} & 30 & -4.92997481 & 2.36687369 & .121 & -10.8365386 & .9765890 \\
\hline & 60 & 1.86712667 & 2.36687369 & .734 & -4.0394371 & 7.7736904 \\
\hline \multirow{2}{*}{60} & 30 & $-6.79710148^{*}$ & 2.36687369 & .020 & -12.7036653 & -.8905377 \\
\hline & 45 & -1.86712667 & 2.36687369 & .734 & -7.7736904 & 4.0394371 \\
\hline
\end{tabular}

* The mean difference is significant at the 0.05 level.

Table 27. The values of the optimal parameters.

\begin{tabular}{ccccc}
\hline & $\boldsymbol{k}$ & $\boldsymbol{n}$ & $\boldsymbol{Q}_{\boldsymbol{k}}$ & $\boldsymbol{T}$ \\
\hline ABC algorithm & 6 & 120 & 60 & 20 \\
ACO algorithm & 4 & 120 & 60 & 20 \\
\hline
\end{tabular}

wide-aisle warehouses. To decrease orders turnover (response time) and sum of the idle times of the operators, limitations of each block transportation device, order quantity, and time needed for each batch formation were investigated and finally a number of the formed batches and orders in each batch were studied subsequently.

The findings of the present study show that the warehouse blocking system affected the reduction of the completion time of warehouse orders. As is clear from the results of different scenarios, this effect is significant. The other important point extracted from this research is that the obtained results are positively correlated to the results of Zhang research which clearly confirms the validity of the presented model. According to the results, it can be said that the ACO algorithm improved more than the $\mathrm{ABC}$ algorithm.

In the past research, there are few and limited studies on order classification in warehouse blocking, and there is no research on online orders in the field of warehouse blocking. Therefore, in future researches, the effects of operator skill on the reduction of the search time should be investigated. Also, the study of the impacts of proper skill training on the goods searching and picking manner is necessary. Another issue that should be considered in the future is the inclusion of queuing systems to prioritize incoming orders in the order batching system. Finally, it is worth noting that adding more operators to each block or using operators as an auxiliary force in a block with a temporary increase in workload can help reduce the response time, thereby improving customer satisfaction.

\section{References}

1. Chen, T.-L., Cheng, C.-Y., Chen, Y.-Y., et al. "An efficient hybrid algorithm for integrated order batching, sequencing and routing problem", International Journal of Production Economics, 159, pp. 158-167 (2015).

2. Rezaei, M., Shirazi, M.A., and Karimi, B. "A multi- 
objective SCOR-based decision alignment for supply chain performance management", Scientia Iranica., Transaction E, Industrial Engineering, 25(5), pp. $2807-2823$ (2018).

3. Bartholdi, J. and Hackman, S. "Warehouse \& distribution science: Release 0.96 . The supply chain and logistics institute, Georgia institute of technology", Atlanta, USA Google Scholar (2014).

4. Tompkins, J.A., White, J.A., Bozer, Y.A., et al. Facilities Planning, John Wiley \& Sons (2010).

5. Le-Duc, T. and de Koster, R.M. "Travel time estimation and order batching in a 2-block warehouse", European Journal of Operational Research, $\mathbf{1 7 6}(1)$, pp. 374-388 (2007).

6. Van Nieuwenhuyse, I. and de Koster, R.B. "Evaluating order throughput time in 2-block warehouses with time window batching", International Journal of Production Economics, 121(2), pp. 654-664 (2009).

7. Melacini, M., Perotti, V., and Tumino, V. "Development of a framework for pick-and-pass order picking system design", The International Journal of Advanced Manufacturing Technology, 53(9-12), pp. 841-854 (2011).

8. Pan, J.C.-H., Shih, P.-H., and Wu, M.-H. "Order batching in a pick-and-pass warehousing system with group genetic algorithm", Omega, 57, pp. 238-248 (2015).

9. Van Nieuwenhuyse, I., de Koster, R., and Colpaert, J. "Order batching in multi-server pick-and-sort warehouses", DTEW-KBI_0731, pp. 1-29 (2007).

10. Henn, S. and Schmid, V. "Metaheuristics for order batching and sequencing in manual order picking systems", Computers \& Industrial Engineering, 66(2), pp. 338-351 (2013).

11. Lee, J.A., Chang, Y.S., Shim, H.-J., et al. "A study on the picking process time", Procedia Manufacturing, 3, pp. $731-738$ (2015).

12. Pérez-Rodríguez, R., Hernández-Aguirre, A., and Jöns, S. "A continuous estimation of distribution algorithm for the online order-batching problem", The International Journal of Advanced Manufacturing Technology, 79(1-4), pp. 569-588 (2015).

13. Scholz, A., Schubert, D., and Wäscher, G. "Order picking with multiple pickers and due dates-simultaneous solution of order batching, batch assignment and sequencing, and picker routing problems", European Journal of Operational Research, 263(2), pp. 461-478 (2017).

14. Henn, S. "Algorithms for on-line order batching in an order picking warehouse", Computers \& Operations Research, 39(11), pp. 2549-2563 (2012).

15. Henn, S. "Order batching and sequencing for the minimization of the total tardiness in picker-to-part warehouses", Flexible Services and Manufacturing Journal, 27(1), pp. 86-114 (2015).
16. Henn, S., Koch, S., and Wöscher, G. "Order batching in order picking warehouses: a survey of solution approaches", Warehousing in the Global Supply Chain, pp. 105-137, Springer (2012).

17. Yu, M. and De Koster, R.B. "The impact of order batching and picking area zoning on order picking system performance", European Journal of Operational Research, 198(2), pp. 480-490 (2009.

18. Zhang, J., Wang, X., Chan, F.T.S., et al. "On-line order batching and sequencing problem with multiple pickers: A hybrid rule-based algorithm", Applied Mathematical Modelling, 45, pp. 271-284 (2017).

19. Ho, Y-C. and Tseng, Y-Y. "A study on order batching methods of order-picking in a distribution centre with two cross-aisles", International Journal of Production Research, 44(17), pp. 3391-3417 (2006).

20. Agarwal, V., Gupta, V., and Singh, P.K. "A systematic review on artificial bee colony optimization technique", International Journal of Control Theory and Application, 9(11), pp. 5487-5500 (2016).

21. Saucedo, L.E.C., Sanchez-Solis, J.P., López-Ramos, F., et al. "Implementation of an Artificial Bee Colony to Solve an Order Picking Problem", Handbook of Research on Metaheuristics for Order, Picking Optimization in Warehouses to Smart Cities, pp. 144-160: IGI Global (2019).

22. Li, Z. and Zhou, V. "An effective batching method based on the artificial bee colony algorithm for order picking", In Ninth International Conference on Natural Computation (ICNC), pp. 386-391 (2013).

23. Blum, C. "Ant colony optimization: Introduction and recent trends", Physics of Life Reviews, 2(4), pp. 353$373(2005)$.

24. Engin, O. and Güçlü, V. "A new hybrid ant colony optimization algorithm for solving the no-wait flow shop scheduling problems", Applied Soft Computing, 72, pp. 166-176 (2018).

25. Jia, Z.-h., Wang, Y., Wu, C., et al. "Multi-objective energy-aware batch scheduling using ant colony optimization algorithm", Computers \& Industrial Engineering, 131, pp. 41-56 (2019).

26. Nia, A.R., Haleh, H., and Saghaei, A. "Energyconscious dynamic sequencing method for dual command cycle unit-load multiple-rack automated storage and retrieval systems", Scientia Iranica., Transaction E, Industrial Engineering, 24(6), pp. 3371-3393 (2017).

27. Marandi, F. and Zegordi, S. "Integrated production and distribution scheduling for perishable products", Scientia Iranica, 24(4), pp. 2105-2118 (2017).

28. Teimoury, E. and Kazemi, S. "An integrated pricing and inventory model for deteriorating products in a two-stage supply chain under replacement and shortage", Scientia Iranica., Transaction E, Industrial Engineering, 24(1), p. 342 (2017). 
29. Chaharsooghi, S. and Sajedinejad, A. "Determination of the number of kanbans and batch sizes in a JIT supply chain system", Scientia Iranica., Transaction E., Industrial Engineering, $\mathbf{1 7}(2)$, p. 143 (2010).

30. Elsayed, E., Lee, M.-K., Kim, S., et al. "Sequencing and batching procedures for minimizing earliness and tardiness penalty of order retrievals", The International Journal of Production Research, 31(3), pp. 727738 (1993).

31. Gu, J., Goetschalckx, M., and McGinnis, L.F. "Research on warehouse operation: A comprehensive review", European Journal of Operational Research, 177(1), pp. 1-21 (2007).

32. Richards, G., Warehouse Management: A Complete Guide to Improving Efficiency and Minimizing Costs in the Modern Warehouse, Kogan Page Publishers (2017).

33. Henn, S., Koch, S., Doerner, K.F., et al. "Metaheuristics for the order batching problem in manual order picking systems", Business Research, 3(1), pp. 82-105 (2010).

34. Henn, S. and Wäscher, G. "Tabu search heuristics for the order batching problem in manual order picking systems", European Journal of Operational Research, 222(3), pp. 484-494 (2012).

35. Li, W., Guo, C., Su, B., et al. "Photodegradation of four fluoroquinolone compounds by titanium dioxide under simulated solar light irradiation", Journal of Chemical Technology \& Biotechnology, 87(5), pp. 643650 (2012).

36. Bahrami, B., Aghezzaf, E.H., and Limere, V. "Using simulation to analyze picker blocking in manual order picking systems", Procedia Manufacturing, 11, pp. 1798-1808 (2017).

37. Van Gils, V, Ramaekers, K., Braekers, K., Depaire, B., and Caris, A. "Increasing order picking efficiency by integrating storage, batching, zone picking, and routing policy decisions", International Journal of Production Economics, 197, pp. 243-261 (2018).

38. Muppani, V.R. and Adil, G.K. "Efficient formation of storage classes for warehouse storage location assignment: A simulated annealing approach", Omega, 36(4), pp. 609-618 (2008).

39. Choe, K.-I., Aisle-Based Order Pick Systems with Batching, Zoning, and Sorting, Georgia Institute of Technology (1990).

40. Tang, L.C. and Chew, E.-P. "Order picking systems: batching and storage assignment strategies", Computers \& Industrial Engineering, 33(3-4), pp. 817-820 (1997).

41. Parikh, P.J. and Meller, R.D. "Selecting between batch and zone order picking strategies in a distribution center", Transportation Res earch Part E: Logistics and Transportation Review, 44(5), pp. 696-719 (2008).

42. Pansart, L., Catusse, N., and Cambazard, H. "Exact algorithms for the order picking problem", Computers \& Operations Research, 100, pp. 117-127 (2018).
43. Matusiak, M., de Koster, R., Kroon, L., et al. "A fast simulated annealing method for batching precedenceconstrained customer orders in a warehouse", European Journal of Operational Research, 236(3), pp. 968-977 (2014).

44. Valle, C.A., Beasley, J.E., and da Cunha, A.S. "Optimally solving the joint order batching and picker routing problem", European Journal of Operational Research, 262(3), pp. 817-834 (2017).

45. Menéndez, B., Pardo, E.G., Alonso-Ayuso, A., et al. "Variable neighborhood search strategies for the order batching problem", Computers \& Operations Research, 78, pp. 500-512 (2017).

46. Menéndez, B., Bustillo, M., Pardo, E.G., et al. "General variable neighborhood search for the order batching and sequencing problem", European Journal of Operational Research, 263(1), pp. 82-93 (2017).

47. Jiang, X., Zhou, Y., Zhang, Y., et al. "Order batching and sequencing problem under the pick-and-sort strategy in online supermarkets", Procedia Computer Science, 126, pp. 1985-1993 (2018).

48. Lin, C.-C., Kang, J.-R., Hou, C.-C., et al. "Joint order batching and picker Manhattan routing problem", Computers \& Industrial Engineering, 95, pp. 164-174 (2016).

49. Hong, S. and Kim, Y. "A route-selecting order batching model with the S-shape routes in a parallel-aisle order picking system", European Journal of Operational Research, 257(1), pp. 185-196 (2017).

50. Chen, M.-C. and Wu, H.-P. "An association-based clustering approach to order batching considering customer demand patterns", Omega, 33(4), pp. 333-343 (2005).

51. Gibson, D.R. and Sharp, G.P. "Order batching procedures", European Journal of Operational Research, 58(1), pp. 57-67 (1992).

52. Gademann, N. and Velde, S. "Order batching to minimize total travel time in a parallel-aisle warehouse", IIE Transactions, 37(1), pp. 63-75 (2005).

53. Kulak, O., Sahin, Y., and Taner, M.E. "Joint order batching and picker routing in single and multiplecross-aisle warehouses using cluster-based tabu search algorithms", Flexible Services and Manufacturing Journal, 24(1), pp. 52-80 (2012).

54. Cergibozan, Ç. and Tasan, A.S. "Order batching operations: an overview of classification, solution techniques, and future research", Journal of Intelligent Manufacturing, 30(1), pp. 1-15 (2016).

\section{Biographies}

Leily Hojaghani received a BS degree from the University of Science and Culture, Tehran, Iran, and an MS degree from Qazvin Islamic Azad University, Qazvin, Iran in Industrial Engineering, She is a PhD student of Industrial Engineering at Islamic Azad University 
Javad Nematian received his $\mathrm{Msc}$ and $\mathrm{PhD}$ in Industrial Engineering from the Sharif University of Technology in 2004 and 2008. From 2007 to 2008, he was with SYSTeM Research Group at the University of Ghent as a visiting researcher. His research interests include integer programming and uncertain mathematical programming. From 2009 to 2014, he was with the Industrial Engineering Department at the University of Tabriz as an Assistant Professor. Since 2014, he has been an Associate Professor in the Industrial Engineering Department at the University of Tabriz. He is a member of the Iranian Operations Research Society. From 2013 to 2018, he was also the Head of the Industrial Engineering Department.

Amir Abbas Shojaie was born in Tehran, Iran, in 1970. He received his $\mathrm{BS}, \mathrm{MS}$, and $\mathrm{PhD}$ degrees in Industrial Engineering from the Tehran University, Science \& Research, Tehran, Iran, in 2003. In 2007, he joined the School of Industrial Engineering, University of Azad, Tehran South Branch, as a Lecturer and after one year he became an Assistant Professor, where he was also dean of master of science students in 2009 till 2016. His current research interests include quality engineering, modeling, and project management optimization with a focus on customer satisfaction and transportation system, productivity, and modeling. Dr. Shojaie is a fellow of the Iranian National Association of Industrial Engineering; the National Quality Science Association, Iran; and the Institution of Engineers (Iran). He is also the quality lead assessor in AENOR, Spain. He is a board member of the Iran Social Responsibility-National Standard Technical Committee, the System Society of Iran. He has published more than 60 journal articles and 20 conference articles and 4 books in the field of Industrial Engineering. He was the General Chair of the International Conference on WTO \& pioneer organization in Iran (2006-2009) held in New Tehran. He was awarded as the Best Researcher of the University in 2012 and the Best Professor of the Faculty. He has the membership of professional institutions of EFQM, IMCA, IRCA, and technical board of ISIRI. Dr. Shojaie is the member of Professional Committee on providing the Iranian National Standard such as ISO 29000, ISO 26000, and ISO 10006.

Mehrdad Javadi received the BSc and MS degrees in Mechanical Engineering from Sharif University, Tehran, Iran, and Tehran University, Tehran, Iran, respectively. He received his $\mathrm{PhD}$ degree from Islamic Azad University, Science and Research Branch, Tehran, Iran. He is also a member of the mechatronics department. His research interests are mechanical-electrical interfaces and advanced manufacturing systems. 